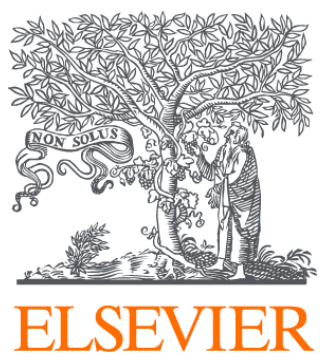

Since January 2020 Elsevier has created a COVID-19 resource centre with free information in English and Mandarin on the novel coronavirus COVID-

19. The COVID-19 resource centre is hosted on Elsevier Connect, the company's public news and information website.

Elsevier hereby grants permission to make all its COVID-19-related research that is available on the COVID-19 resource centre - including this research content - immediately available in PubMed Central and other publicly funded repositories, such as the WHO COVID database with rights for unrestricted research re-use and analyses in any form or by any means with acknowledgement of the original source. These permissions are granted for free by Elsevier for as long as the COVID-19 resource centre remains active. 


\title{
Evaluating the potential of adaptive comfort approach using historic data to reduce energy consumption in buildings in southern Spain
}

\author{
David Bienvenido-Huertas $^{\mathrm{a}, *}$, Carlos Rubio-Bellido ${ }^{\mathrm{a}}$, Fátima Farinha ${ }^{\mathrm{b}}$, Miguel José Oliveira ${ }^{\mathrm{b}}$, \\ Juan Luis Pérez-Ordóñez ${ }^{c}$ \\ ${ }^{a}$ University of Seville, Department of Graphical Expression and Building Engineering, Av. Reina Mercedes 4A, 41012, Seville, Spain \\ ${ }^{\mathrm{b}}$ University of Algarve, Institute of Engineering, Campus da Penha, 8005-139, Faro, Portugal \\ ${ }^{\mathrm{c}}$ University of A Coruña, Department of Civil Engineering, E.T.S.I. Caminos, Canales, y Puertos. Campus Elviña, s/n, 15071, A Coruña, Spain
}

\section{A R T I C L E I N F O}

\section{Keywords:}

Adaptive comfort

Energy saving

Adaptive setpoint temperature

Natural ventilation

Andalusia

\begin{abstract}
A B S T R A C T
The application of adaptive comfort models is among the determinant factors to reduce greenhouse gas emissions in the building sector. This research studies the region of Andalusia (south of Spain). A cluster analysis is applied to 786 Andalusian municipalities, and 4 groups are established according to the potential of adaptive strategies. A town is chosen from each group, and an hourly specific study is conducted for the last 20 years, as well as a daily study of the old time series by using an artificial neural network based on the existing climate data. The possibility of application of the EN 16798-1:2019 standard during the days of the year is analysed, as well as the possibilities of using natural ventilation and the possibility of using adaptive setpoint temperatures in comparison with both 3 fixed heating temperatures and 3 fixed cooling temperatures by considering the energy saving. The results to apply the standard ranged 69.0 and $100 \%$ of the days of each year. The possibilities of natural ventilation considered were greater than $10 \%$ of the hours of the year in all the assumptions. The energy saving of cooling degrees reveals a greater potential in the area studied than that of heating degrees; this tendency is supported by the study of old temporary series which are part of the climate variation predicted throughout the 21 st century.
\end{abstract}

\section{Introduction}

Climate change and environmental degradation can soon become a turning point in global history, mainly caused by continuous greenhouse gas (GHG) emissions speeding up global warming and the acidification of oceans. These aspects have been included in various reports of the Intergovernmental Panel on Climate Change (IPCC), which analyses different future scenarios characterised by increases in temperature and sea level $[1,2]$. It is, therefore, essential to take action against the main GHG emitters. In this regard, various countries committed to reducing GHG emissions in the 2015 Paris Climate Conference, although these objectives are today far from being fulfilled [3]. Nonetheless, these objectives established the need that no human activity should produce GHG emissions. Among the major activities, those generating maximum emissions include the use of buildings, which are responsible for $36 \%$ of the GHG emissions in the atmosphere [4,5]. Thus, one of the objectives set by the European Union is to reduce the emissions generated by buildings by $90 \%$ by 2050 [6].
To achieve these objectives, taking action on one of the main building consumptions, i.e. the use of heating, ventilation and air conditioning (HVAC) systems, is required [7]. For this purpose, a tendency in professional actions and research studies has been to analyse envelope designs that indicate the reduction in heat transfer to the exterior, improvement in HVAC systems, and personal use. These improvements, however, can produce rebound effects, leading to high energy consumption by users [8]. Thus, another factor playing an important role in HVAC system energy consumption is user behaviour [9]. A fundamental aspect in establishing an appropriate user behaviour with respect to the use of HVAC systems is controlling the setpoint temperature. In this regard, considerable research has analysed the energy-saving achieved with the modification of the setpoint temperature by following static-use patterns. For example, Wan et al. [10] analysed the reduction in energy consumption in future climate-change scenarios in several case studies conducted in Hong Kong by modifying the setpoint temperature. These authors achieved substantial decreases in energy consumption under different scenarios by using cooling setpoint temperatures above $25.5^{\circ} \mathrm{C}$. Other related studies include those conducted by Spyropoulos

\footnotetext{
* Corresponding author.

E-mail address: jbienvenido@us.es (D. Bienvenido-Huertas).
} 


\begin{tabular}{|c|c|c|}
\hline \multirow[t]{2}{*}{ Nomenclature } & $s(i)$ & silhouette index \\
\hline & $T_{A C, i}$ & Hourly value of adaptive setpoint temperature for cooling \\
\hline Symbols & & {$\left[{ }^{\circ} \mathrm{C}\right]$} \\
\hline \multirow{2}{*}{$\begin{array}{l}\text { Adaptive } C D \text { Annual sum of hourly cooling degrees between adaptive } \\
\text { setpoints and the external temperature }\left[{ }^{\circ} \mathrm{C}\right]\end{array}$} & $T_{A H, i}$ & Hourly value of adaptive setpoint temperature $\left[{ }^{\circ} \mathrm{C}\right]$ \\
\hline & $T_{\text {ext }, d}$ & Hourly value of external temperature $\left[{ }^{\circ} \mathrm{C}\right]$ \\
\hline \multirow{2}{*}{$\begin{array}{l}\text { AdaptiveHD Annual sum of hourly heating degrees between adaptive } \\
\text { setpoints and the external temperature }\left[{ }^{\circ} \mathrm{C}\right]\end{array}$} & $T_{\text {ext }, i}$ & nourny value or exieninal temperature [C] \\
\hline & $T_{S C, R, i}$ & hourly value of static setpoint temperature for cooling $\left[{ }^{\circ} \mathrm{C}\right]$ \\
\hline $\begin{array}{l}a(i) \quad \text { Average distance between an individual (i) and the } \\
\text { remaining points of the same group }\end{array}$ & $T_{S H, R, i}$ & $\begin{array}{l}\text { Hourly value of static setpoint temperature for heating } \\
{\left[{ }^{\circ} \mathrm{C}\right]}\end{array}$ \\
\hline \multirow{2}{*}{$\begin{array}{ll}\text { BSS/TSS } & \text { Ratio between sum of squares and total sum of square } \\
b(i) & \text { Minimum average distance between the individual and the } \\
& \text { others }\end{array}$} & $t_{i}$ & Actual value \\
\hline & $\begin{array}{l}t_{r m} \\
\text { WSS }\end{array}$ & $\begin{array}{l}\text { Running mean outdoor temperature } \\
\text { Total within-cluster sum of squares }\end{array}$ \\
\hline \multirow{2}{*}{$\begin{array}{ll}d_{i} & \text { Value assigned to each day of the year } \\
h_{i} & \text { Value assigned to each hour of the year } \\
M A E & \text { Mean absolute error }\end{array}$} & $w_{k 0}^{(1)}$ & Weight of the bias neuron of the input layer \\
\hline & $w_{k j}^{(1)}$ & Weights of the hidden layer \\
\hline$m_{i} \quad$ Model's prediction & $w_{l 0}^{(2)}$ & Weight of the bias neuron of the hidden layer \\
\hline NDY Number of days of the year & $w_{l k}^{(2)}$ & Weights of the output layer \\
\hline NHY $\quad$ Number of hours of the year & $X_{C A}$ & Logic values \\
\hline NI Number of nodes of the input layer & $X_{C S}$ & Logic values \\
\hline NO Number of nodes of the output layer & $X_{H A}$ & Logic values \\
\hline Number of instances in the dataset & $X_{H S}$ & Logic values \\
\hline $\begin{array}{l}\text { Percentage of days of the year in which the adaptive } \\
\text { thermal comfort model could be applied [\%] }\end{array}$ & $x_{0}$ & Input value of the bias neuron of the input layer \\
\hline Percentage of hours to apply adaptive natural ventilation & $x_{j}$ & Values of the input layer \\
\hline strategies [\%] & $\widehat{Y}_{M L P}$ & Estimation performed by the multilayer perceptron \\
\hline Reference value selected for static setpoint temperatures & $y_{0}$ & Input value of the bias neuron of the hidden layer \\
\hline 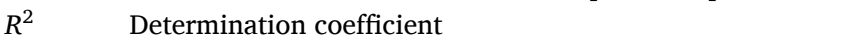 & $y_{k}$ & output value of a neuron of the hidden layer \\
\hline \multirow{2}{*}{$\begin{array}{ll}R M S E & \text { Root mean square error } \\
S C D H_{R} & \text { Annual saving in cooling degrees of cooling adaptive } \\
& \text { setpoints with respect to static setpoints of } R \text {-value }\left[{ }^{\circ} \mathrm{C}\right]\end{array}$} & \multicolumn{2}{|c|}{ Greek letters } \\
\hline & $\sigma$ & Activation function \\
\hline \multirow{2}{*}{ 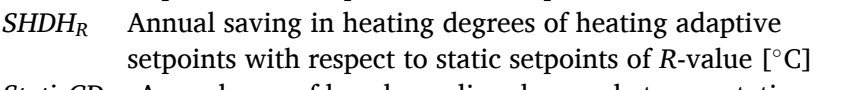 } & Abbrevi & ions \\
\hline & GHG & Greenhouse gas \\
\hline \multirow{2}{*}{$\begin{array}{c}\text { StaticCD } D_{R} \text { Annual sum of hourly cooling degrees between static } \\
\text { setpoints and the external temperature }\left[{ }^{\circ} \mathrm{C}\right]\end{array}$} & HVAC & Heating, ventilation and air conditioning \\
\hline & IPCC & Intergovernmental Panel on Climate Change \\
\hline $\begin{aligned} & \text { StaticHD } \text { Annual sum of hourly heating degrees between static } \\
& \text { setpoints and the external temperature }\left[{ }^{\circ} \mathrm{C}\right]\end{aligned}$ & MLP & Multilayer perceptron \\
\hline
\end{tabular}

and Balaras [11] and Hoyt et al. [12], who analysed the possibility of reducing the total energy consumption of office buildings by modifying the heating and cooling setpoint temperatures, thus obtaining between $45 \%$ and $73 \%$ energy savings. Despite these results, the above-mentioned studies were based on static criteria, thus in turn, based on Fanger's thermal models [13]. These models present a static behaviour of thermal comfort limits with a narrow range between the lower and upper limits. Meanwhile, an increasing number of studies are considering the possibility of using adaptive thermal comfort models $[14,15]$. In these models, users can modify their thermal comfort by adapting their behaviour, and compared to Fanger's static thermal comfort approaches, the building energy consumption can be reduced by limiting the use of HVAC systems [16]. The development of these comfort models began in the 1970s by Humphreys [17,18] and Nicol and Humphreys [19], who found that the thermal comfort models obtained from the laboratory did not fit the buildings operating with natural ventilation. Likewise, the adaptabilities of users to the interior conditions were detected. Subsequently, de Dear and Brager [20] conducted 21,000 field observations and formalised the concept of adaptive thermal comfort. After the later studies by Dear and Brager [21,22], ASHRAE-55:2004 was the first thermal comfort standard to include an adaptive thermal comfort model with the data obtained through the ASHRAE RP-884 project [15]. In Europe, the data obtained through the Smart Control and Thermal Comfort project [23] were used to develop an adaptive thermal comfort model that was integrated into the standard EN 15251:2007 [24]. Subsequently, the European standard was modified with the standard EN 16798-1:2019 [25]. This modification also proposed changes in the possibilities of applying the adaptive thermal comfort model, such as the temperature difference between the lower limit and the optimum temperature [26].

A fundamental aspect of adaptive thermal comfort models is that users can adapt to climatic variations through different strategies (also known as adaptive strategies). In this sense, one of the strategies is related to using HVAC systems. The adaptive strategies can be distinguished into two topologies: natural ventilation and adaptive setpoint temperatures. Natural ventilation involves the possible acclimatisation of the indoor space when the external temperature is within appropriate thermal comfort limits for users, thus reducing the use of HVAC systems [27-29]. On the other hand, adaptive setpoint temperatures are configured according to the external temperatures and the adaptive thermal comfort model used, thus reflecting users' adaptability to climate variations with up to $50 \%$ energy-saving with respect to static setpoint temperatures [30-33].

The effectiveness of applying these measures mainly depends on the climate in which the building is located. A previous study [34] assessed the possibilities of applying adaptive strategies globally. The results showed great possibilities of applying adaptive thermal comfort models globally, particularly in zones such as the Mediterranean. This study, however, was based on the analyses of average climate files, and thus, did not study the recent evolution. Likewise, this study considered that the use of detailed local analyses would deeply indicate the possibility of applying these strategies. For this reason, the potential applications of 
Table 1

Climate files used in the study, indicating the type of temperature variable available and the period of data.

\begin{tabular}{|c|c|c|c|c|c|c|c|c|}
\hline \multirow[t]{2}{*}{ Cluster } & \multirow[t]{2}{*}{ City } & \multirow[t]{2}{*}{ Latitude } & \multirow[t]{2}{*}{ Longitude } & \multirow[t]{2}{*}{ Altitude } & \multicolumn{2}{|c|}{ Hourly temperature values } & \multicolumn{2}{|c|}{ Daily temperature values (average, minimum, and maximum) } \\
\hline & & & & & Start year & End year & Start year & End year \\
\hline 1 & Cadiz & 36.49972 & -6.25778 & 2 & 2000 & 2019 & 1956 & 1999 \\
\hline 2 & Jaen & 37.77750 & -3.80889 & 580 & 2000 & 2019 & 1989 & 1999 \\
\hline 3 & Grazalema & 36.76799 & -5.36589 & 913 & 2001 & 2019 & - & - \\
\hline 4 & Seville & 37.41667 & -5.87917 & 34 & 2000 & 2019 & 1951 & 1999 \\
\hline
\end{tabular}

Table 2

Main technical specifications of the temperature probe of each weather station.

\begin{tabular}{|c|c|c|c|c|c|}
\hline Cluster & City & Manufacturer & Model & Measuring range & Accuracy \\
\hline 1 & Cadiz & Thies & 1.1005 .54 .700 & $-30-70^{\circ} \mathrm{C}$ & $\pm 0.2{ }^{\circ} \mathrm{C}$ \\
\hline 2 & Jaen & Thies & 1.1005 .54 .700 & $-30-70{ }^{\circ} \mathrm{C}$ & $\pm 0.2{ }^{\circ} \mathrm{C}$ \\
\hline 3 & Grazalema & Thies & 1.1005 .51 .015 & $-30-50^{\circ} \mathrm{C}$ & $\pm 0.2^{\circ} \mathrm{C}$ \\
\hline 4 & Seville & VAISALA & HMP45D & $-40-60{ }^{\circ} \mathrm{C}$ & $\pm 0.2^{\circ} \mathrm{C}$ \\
\hline
\end{tabular}

adaptive strategies between the 20th and 21st centuries were analysed in the region of Andalusia (south of Spain). This region was chosen due to the following three reasons: (i) the potential application found in the global study conducted in this region was high, although regions with a lower application were also found; (ii) the studies on the potential application of adaptive setpoint temperatures and natural ventilation in actual case studies were conducted in some cities of the region (e.g. Seville [30-33]); and (iii) the existing energy poverty risk in the region [35]. In this regard, the Spanish Institute of Statistics determined that Andalusia presents the highest percentage of population with risk poverty and/or exclusion (35.4\%), with the national average being $22.3 \%$ for 2016 [36]. Likewise, Herrero et al. [37] showed that 5.1 million people in Spain (11\% households) cannot maintain their dwelling under appropriate thermal conditions, thus increasing the number of households with energy poverty by $22 \%$ in barely two years and identifying Andalusia as one of the main affected regions.

Thus, the Andalusian building stock requires strategies to reduce the building energy consumption. For this reason, the present study analyses the possibilities of applying the recent adaptive energy-saving strategies. First, a cluster analysis is conducted to classify the 786 Andalusian municipalities. Based on the classification result, a representative city is selected by each cluster and the possibilities of applying adaptive strategies are analysed according to the existing temperature records from the mid-20th century to 2019. In the analysis, multilayer perceptrons (MLPs) are used to estimate the variables of hourly energy-saving based on the available daily data.

\section{Methodology}

\subsection{Adaptive thermal comfort model: EN 16798-1:2019}

The adaptive thermal comfort model developed for Europe is included in EN 16798-1:2019 [25], which is the adaptive thermal comfort standard applicable to all of Europe and constitutes the modification of the previous standard (EN 15251:2007 [24]). The standard establishes three categories of thermal comfort-categories I, II, and III-each of which establishes different recommendations for use: category I is recommended for users with less thermal adaptation (e.g. the elderly, sick, or children), while categories II and III are recommended for new and existing buildings, respectively. In addition, each category establishes lower and upper temperature limits for the indoor operative temperature, which are calculated using linear regression with respect to the running mean outdoor temperature $\left(t_{r m}\right)$ (Eq. (1)-(7)). In this case, EN $16798-1: 2019$ is applicable when $t_{r m}$ is within $10{ }^{\circ} \mathrm{C}$ and $30{ }^{\circ} \mathrm{C}$. $t_{r m}=(1-\alpha) \cdot \sum_{d=1}^{n}\left(\alpha^{(i-1)} \cdot T_{e x t, d}\right)$

Upper limit $($ Category $I)=0.33 \cdot t_{r m}+20.8 \quad\left(10 \leq t_{r m} \leq 30\right)$

Lower limit $($ Category $I)=0.33 \cdot t_{r m}+15.8 \quad\left(10 \leq t_{r m} \leq 30\right)$

Upperlimit $($ CategoryII $)=0.33 \cdot t_{r m}+21.8 \quad\left(10 \leq t_{r m} \leq 30\right)$

Lowerlimit $($ CategoryII $)=0.33 \cdot t_{r m}+14.8 \quad\left(10 \leq t_{r m} \leq 30\right)$

Upperlimit $($ CategoryIII $)=0.33 \cdot t_{r m}+22.8 \quad\left(10 \leq t_{r m} \leq 30\right)$

Lower limit $($ CategoryIII $)=0.33 \cdot t_{r m}+13.8 \quad\left(10 \leq t_{r m} \leq 30\right)$

The use of these adaptive thermal comfort models allows adaptive energy-saving measures to be adopted. These measures are mainly based on two aspects: (i) the use of natural ventilation during the hours in which the external temperature is within the application limits of EN 16798-1:2019 and (ii) the use of HVAC systems through adaptive setpoint temperatures when the indoor space cannot be naturally ventilated. If the $t_{r m}$ value is beyond the application limits of the standards (e. g. lower than $10^{\circ} \mathrm{C}$ or greater than $30^{\circ} \mathrm{C}$ in EN 16798-1:2019), a fixed value should be used for the adaptive setpoint temperatures, corresponding to the horizontal extension of the limit values of the adaptive model [38].

\subsection{Analysis process of adaptive strategies}

The process of analysing the climate data involves assessing the possibilities of applying the adaptive thermal comfort models and hourly saving of heating and cooling degrees by following the same criterion of data analysis as that mentioned in a previous study [34]. For this purpose, in the next subsections, the procedure followed in the previous study is described separately in relation to the possibility of applying adaptive thermal comfort models in Andalusia and the energy-saving potential that can be achieved through the adaptive strategies.

\subsubsection{Application of adaptive thermal comfort models}

The possibility of applying the models was achieved in accordance with the application criteria of EN 16798-1:2019, where $t_{r m}$ was assumed to be within the application limits of EN 16798-1:2019 (i.e. between $10{ }^{\circ} \mathrm{C}$ and $30{ }^{\circ} \mathrm{C}$ ). Note that in this case, it is not necessary to distinguish between the EN 16798-1:2019 categories, because they all follow the same criteria. The application analysis was performed on a daily scale, because the $t_{r m}$ value is associated with the average daily 

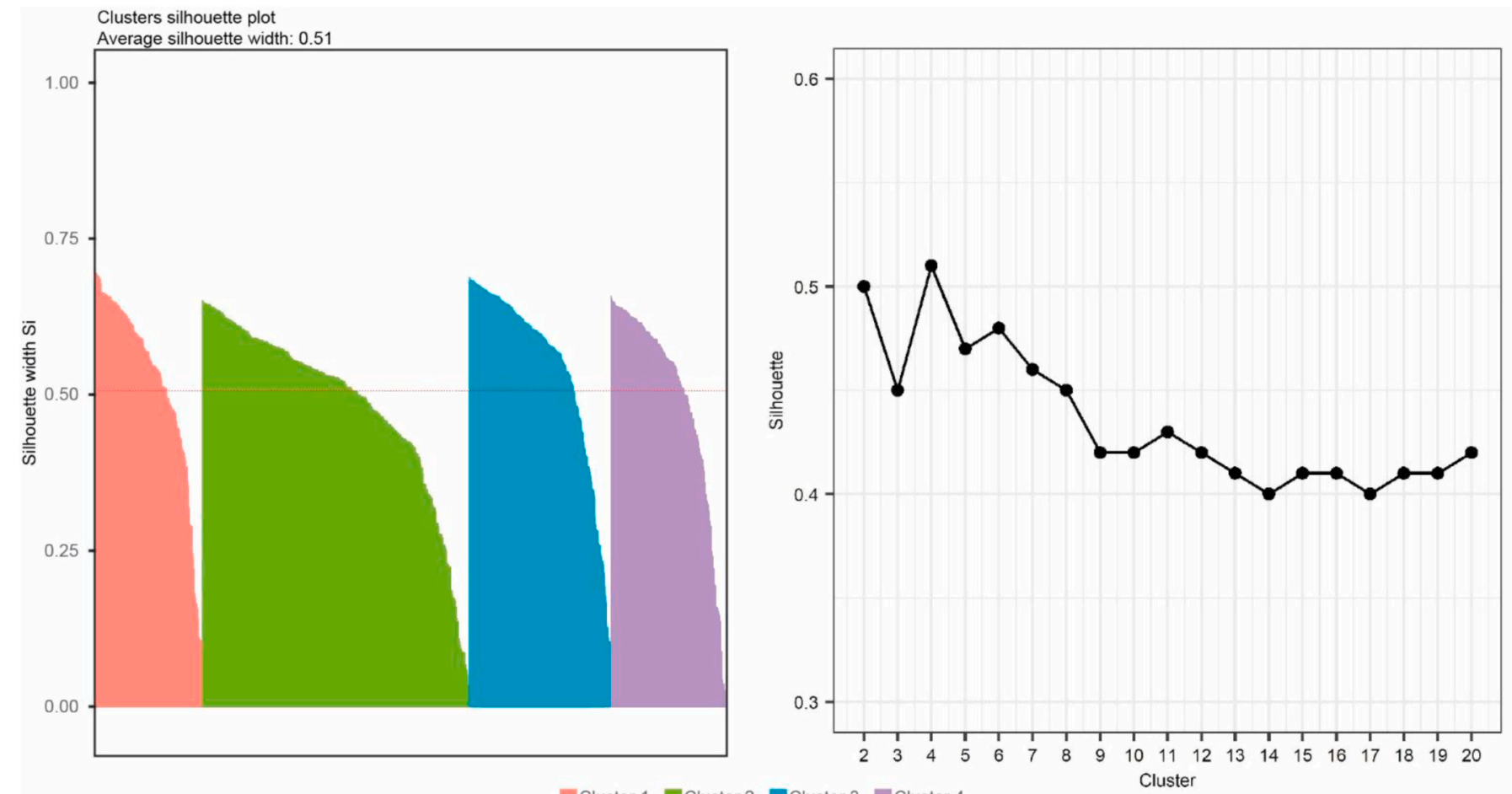

a Cluster 1 Cluster 2 Cluster 3 Cluster 4

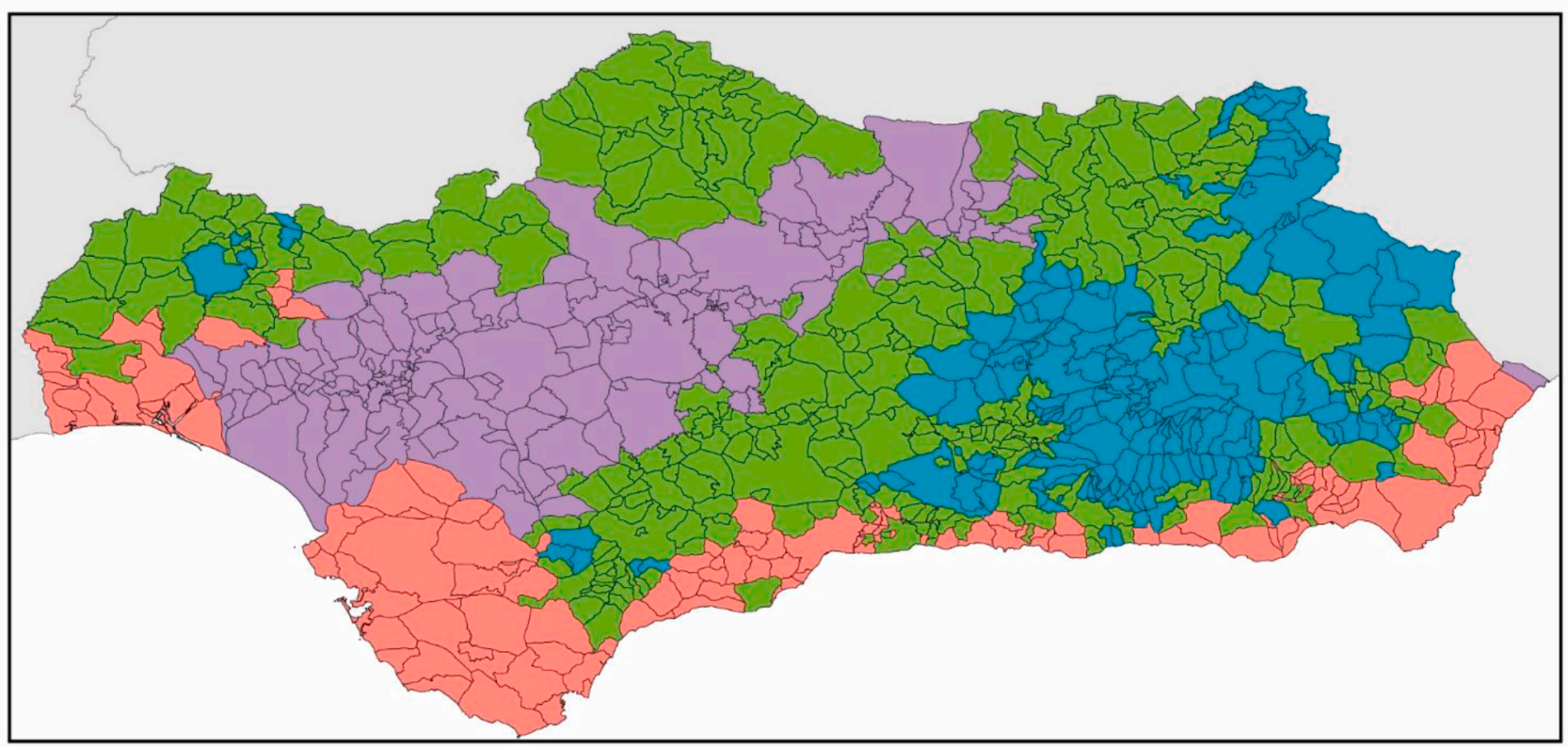

Fig. 1. Results of the cluster analysis.

temperatures. Therefore, the number of days for which $t_{r m}$ was within the limits of application and EN 16798-1:2019 was determined and evaluated with respect to the year total. The $t_{r m}$ value was determined using the data obtained from previous 15 days, with an $\alpha$-value of 0.8 .

$$
\begin{aligned}
& \text { PDAAM }=100 \cdot \frac{\sum_{i=1}^{N D Y} d_{i}}{N D Y} \\
& d_{i}=1 \quad \text { if } 30 \geq t_{r m} \geq 10 \\
& d_{i}=0 \quad \text { if } t_{r m}<10 \\
& d_{i}=0 \quad \text { if } t_{r m}>30
\end{aligned}
$$

where PDAAM is the percentage of days of the year in which the adaptive thermal comfort model could be applied [\%], $d_{i}$ is a value assigned to each day of the year, and NDY is the number of days of the year (365 days for non-leap years and 366 days for leap years). If $t_{r m}$ is within the application limits, then a value of 1 is assigned. If not, a value of 0 is then assigned.

\subsubsection{Adaptive energy-saving strategies}

Adaptive strategies were hourly analysed in different manners for natural ventilation and adaptive setpoint temperatures.

2.2.2.1. Natural ventilation. The natural ventilation potential was evaluated on an hourly scale, using an approach similar to that shown in Eq. (8). In this case, the number of annual hours for which the outside temperature remained between the upper and lower limits of adaptive 


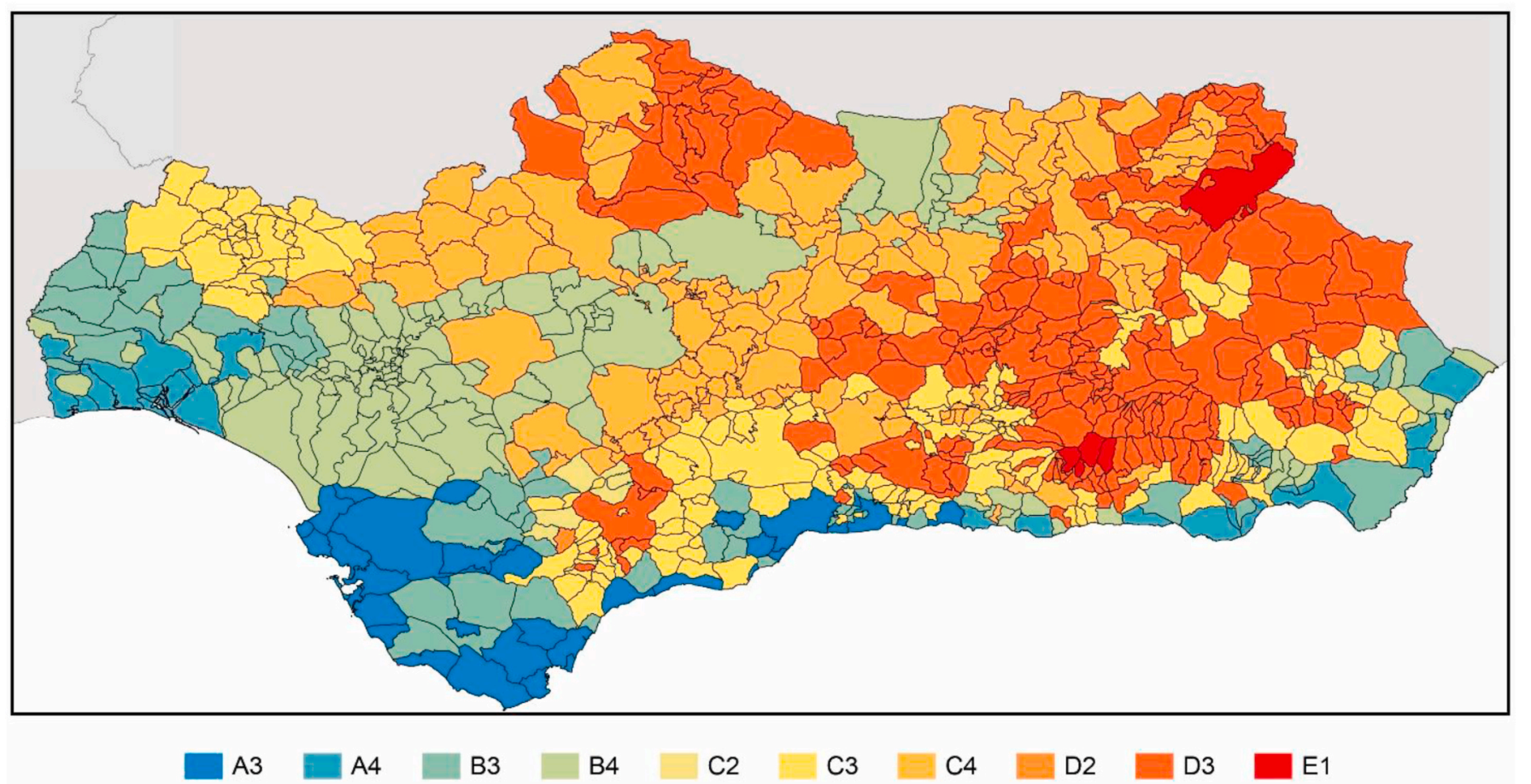

(a)

\begin{tabular}{|c|c|c|c|c|}
\cline { 2 - 5 } \multicolumn{1}{c|}{} & Cluster 1 & Cluster 2 & Cluster 3 & Cluster 4 \\
\hline A3 & 100.00 & 0.00 & 0.00 & 0.00 \\
\hline A4 & 96.15 & 0.00 & 0.00 & 3.85 \\
\hline B3 & 65.52 & 22.41 & 0.00 & 12.07 \\
\hline B4 & 19.17 & 1.67 & 0.00 & 79.17 \\
\hline C2 & 0.00 & 60.00 & 40.00 & 0.00 \\
\hline C3 & 5.41 & 84.86 & 9.73 & 0.00 \\
\hline C4 & 0.71 & 70.21 & 1.42 & 100.00 \\
\hline D2 & 0.00 & 0.00 & 100.00 & 0.00 \\
\hline D3 & 0.00 & 26.15 & 73.85 & 0.00 \\
\hline E1 & 0.00 & 0.00 & 100.00 & 0.00 \\
\hline
\end{tabular}

(b)

Fig. 2. (a) Climatic zones established by the Spanish Technical Building Code and (b) heatmap with the percentages of climatic zones by cluster.

thermal comfort was evaluated (Eq. (9)). Through this criterion, users were assured that the outside temperature was adequate to ensure thermal comfort and that counterproductive effects generated by natural ventilation were avoided [39]. Moreover, for natural ventilation, it is necessary to distinguish the EN 16798-1:2019 categories because each of them has a different equation for the upper and lower limits. Therefore, natural ventilation analysis was performed independently for each category.

$$
\begin{aligned}
& P H N V=100 \cdot \frac{\sum_{i=1}^{N H Y} h_{i}}{N H Y} \\
& h_{i}=1 \quad \text { ifUpperlimit } \geq T_{\text {ext }, i} \geq \text { Lower limit } \\
& h_{i}=0 \quad \text { if } T_{\text {ext }, i}<\text { Lower limit } \\
& h_{i}=0 \quad \text { if } T_{\text {ext }, i}>\text { Upper limit }
\end{aligned}
$$

where $P H N V$ is the percentage of hours to apply adaptive natural ventilation strategies [\%], $h_{i}$ is a value assigned to each hour of the year, $T_{\text {ext }, i}$ is the hourly value of external temperature $\left[{ }^{\circ} \mathrm{C}\right]$, and $N H Y$ is the number of hours of the year $(8760 \mathrm{~h}$ for non-leap years and $8784 \mathrm{~h}$ for leap years). If the hourly outside temperature is within the limits of acceptability, it is assigned a value of 1 , and a value of 0 is assigned when it does not meet this condition.

2.2.2.2. Adaptive setpoint temperatures. Adaptive setpoint temperatures acquire the upper and lower limit values of adaptive thermal comfort models [39]. Thus, for heating at the setpoint temperature, the lower limit is used (Eq. (10)), while for cooling at this temperature, the upper limit is used (Eq. (11)). This assumes that the adaptive setpoint temperatures vary each day according to the variations in the upper and lower limits. Similar to natural ventilation, the adaptive setpoint temperatures must distinguish the category of EN 16798-1:2019 used. Therefore, the following three approaches can be used for adaptive 

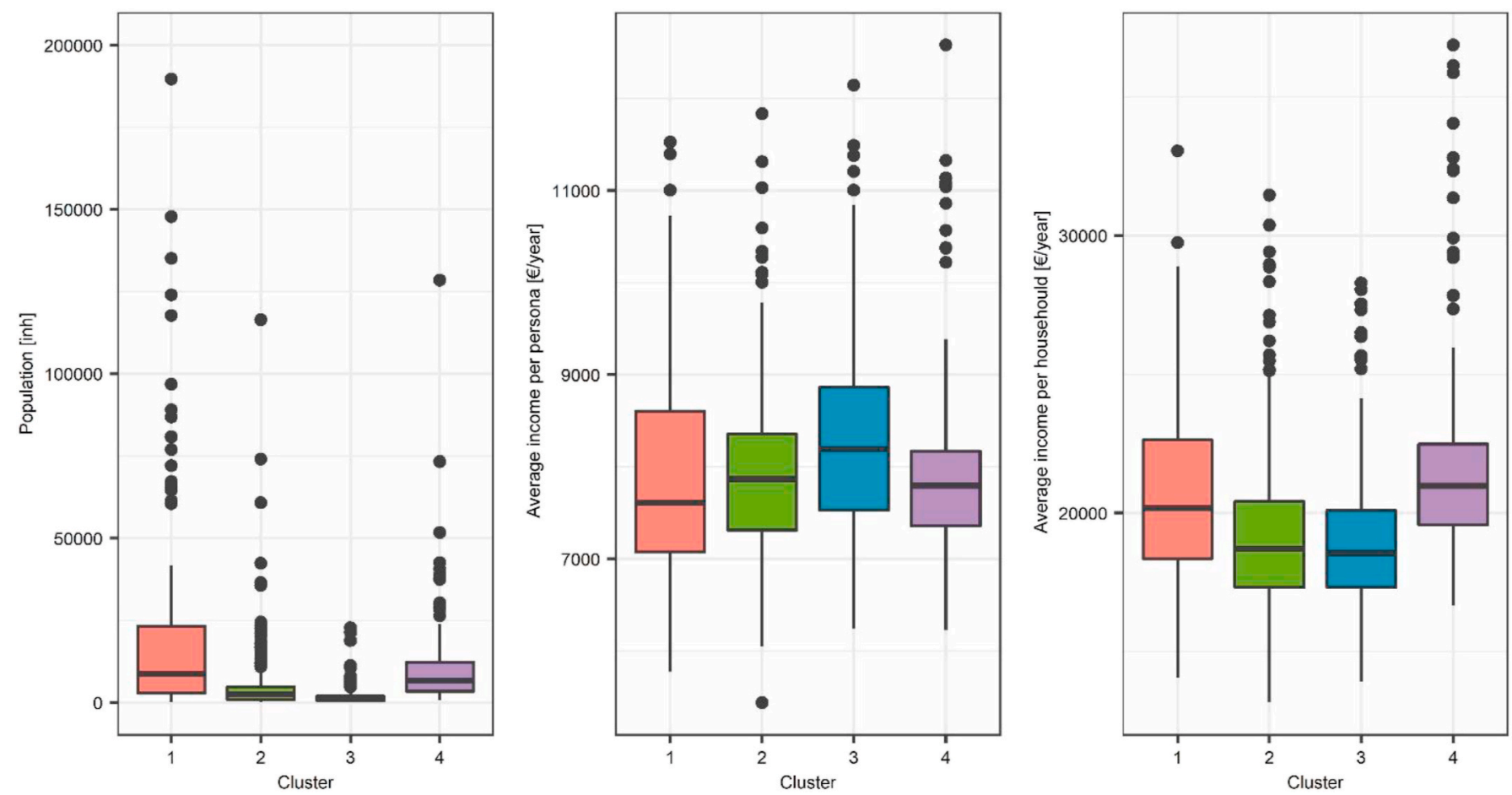

Fig. 3. Box plots with the data distributions of people and of average income per person and per household in each cluster.

Table 3

Quartile of the data distributions of population and average incomes in clusters.

\begin{tabular}{|c|c|c|c|c|c|c|c|c|c|}
\hline \multirow[t]{2}{*}{ Cluster } & \multicolumn{3}{|c|}{ Population [inh.] } & \multicolumn{3}{|c|}{ Average incomes per person [ $€ /$ year $]$} & \multicolumn{3}{|c|}{ Average incomes per household [ $€ /$ year] } \\
\hline & Q1 & Q2 & Q3 & Q1 & Q2 & Q3 & Q1 & Q2 & Q3 \\
\hline 1 & 2878 & 8896 & 23,482 & 7063.00 & 7608.50 & 8604.00 & $18,343.00$ & $20,175.00$ & $22,645.00$ \\
\hline 2 & 927 & 2472 & 4900 & 7310.50 & 7865.00 & 8355.50 & $17,322.50$ & $18,703.50$ & $20,429.50$ \\
\hline 3 & 470 & 1043 & 2026 & 7526.00 & 8187.50 & 8873.00 & $17,327.00$ & $18,551.50$ & $20,100.00$ \\
\hline 4 & 3449 & 7011 & 12,773 & 7354.00 & 7795.00 & 8171.00 & $19,586.00$ & $20,975.00$ & $22,498.00$ \\
\hline
\end{tabular}

setpoint temperatures depending on the category used.

$T_{A H, i}=$ Lowerlimit

$T_{A C, i}=$ Upperlimit

where $T_{A H, i}$ is the hourly value of adaptive setpoint temperature $\left[{ }^{\circ} \mathrm{C}\right]$, and $T_{A C, i}$ is the hourly value of adaptive setpoint temperature for cooling $\left[{ }^{\circ} \mathrm{C}\right]$.

The energy-saving potential with adaptive set temperatures was evaluated for the savings achieved in the heating and cooling degrees with respect to the static setpoint temperatures. First, the summation of the hourly degrees of heating (Eq. (12)) and cooling (Eq. (13)) was determined for a more accurate knowledge of the energy demand of buildings with adaptive strategies. Hourly degrees are based on the rates of cooling and heating degree days to determine the demands of HVAC systems [40]. Both heating and cooling degree days are determined by the difference between the average daily outside temperature and average space temperature. However, this approach does not provide an exact knowledge of the daily thermal oscillations that can vary the energy demand of buildings. In this circumstance, the analysis at an hourly scale provides a more detailed knowledge of the possible energy demand of the buildings [41].

$$
\begin{aligned}
& \text { Adaptive } H D=\sum_{i=1}^{N H Y}\left(T_{e x t, i}-T_{A H, i}\right) \cdot X_{H A} \\
& X_{H A}=1 \text { if } T_{e x t, i}<T_{A H, i} \\
& X_{H A}=0 \text { if } T_{e x t, i} \geq T_{A H, i} \\
& \text { Adaptive } C D=\sum_{i=1}^{N H Y}\left(T_{A C, i}-T_{e x t, i}\right) \cdot X_{C A} \\
& X_{C A}=1 \text { if } T_{e x t, i}>T_{A C, i} \\
& X_{C A}=0 \text { if } T_{e x t, i} \leq T_{A C, i}
\end{aligned}
$$

where AdaptiveHD is the annual sum of hourly heating degrees between adaptive setpoints and the external temperature $\left[{ }^{\circ} \mathrm{C}\right]$, Adaptive $C D$ is the annual sum of hourly cooling degrees between adaptive setpoints and the external temperature $\left[{ }^{\circ} \mathrm{C}\right]$, and $X_{H A}$ and $X_{C A}$ are logic values whose value will be 1 when the condition given in the equations is met, and 0 when not.

The hourly degrees of heating and cooling with an adaptive behaviour were compared with those obtained with static operational patterns by the users. For this purpose, the hourly degrees of heating (Eq. (14)) and cooling (Eq. (15)) were determined using a static setpoint temperature as the base temperature. Three temperatures were selected for heating $\left(20^{\circ} \mathrm{C}, 21^{\circ} \mathrm{C}\right.$, and $\left.22^{\circ} \mathrm{C}\right)$ and three for cooling $\left(25^{\circ} \mathrm{C}, 26^{\circ} \mathrm{C}\right.$, and $27^{\circ} \mathrm{C}$ ) following the same criteria as those used previously [34]. These static temperature values were selected according to the values collected in different standards and regulations [24,42]. 

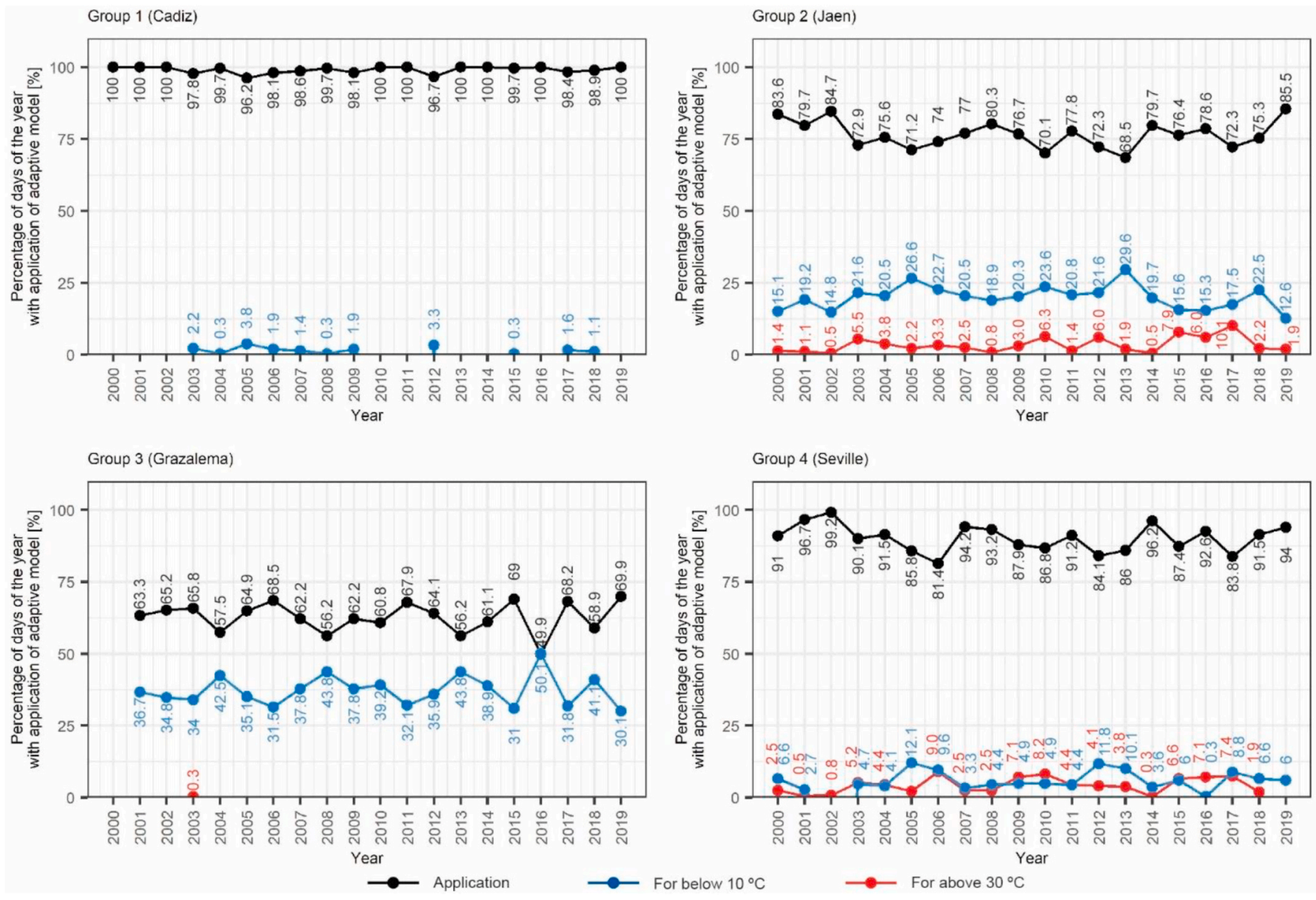

Fig. 4. Possibilities of application of the adaptive thermal comfort models from EN 16798-1:2019 in the period between 2000 and 2019.

$$
\begin{aligned}
& \text { StaticHD }_{R}=\sum_{i=1}^{N H Y}\left(T_{e x t, i}-T_{S H, R, i}\right) \cdot X_{H S} \\
& X_{H S}=1 \text { if } T_{e x t, i}<T_{S H, R, i} \\
& X_{H S}=0 \text { if }_{\text {ext }, i} \geq T_{S H, R, i} \\
& \text { StaticCD } D_{R}=\sum_{i=1}^{N H Y}\left(T_{S C, R, i}-T_{e x t, i}\right) \cdot X_{C S} \\
& X_{C S}=1 \text { if } T_{e x t, i}>T_{S C, R, i} \\
& X_{C S}=0 \text { if } T_{\text {ext }, i} \leq T_{S C, R, i}
\end{aligned}
$$

where StaticHD $D_{R}$ is the annual sum of hourly heating degrees between static setpoints and the external temperature $\left[{ }^{\circ} \mathrm{C}\right]$, Static $C D_{R}$ is the annual sum of hourly cooling degrees between static setpoints and the external temperature $\left[{ }^{\circ} \mathrm{C}\right], T_{S H, R, i}$ is the hourly value of static setpoint temperature for heating $\left[{ }^{\circ} \mathrm{C}\right], T_{S C, R, i}$ is the hourly value of static setpoint temperature for cooling $\left[{ }^{\circ} \mathrm{C}\right], R$ is the reference value selected for static setpoint temperatures (in the case of heating temperatures $R$ has values of 20,21 and $22^{\circ} \mathrm{C}$, and in the case of cooling temperatures $R$ has values of 25,26 and $27^{\circ} \mathrm{C}$ ), and $X_{H S}$ and $X_{C S}$ are logic values whose value will be 1 when the condition given in the equations is met, and 0 when not.

Once the hourly degrees of heating and cooling were determined with both the adaptive and static strategies, the savings in degrees obtained with the adaptive approach for both heating and cooling were determined:

$$
\begin{aligned}
& S H D H_{R}=\text { StaticHD }_{R}-\text { AdaptiveHD } \\
& S C D H_{R}=\text { StaticCD } D_{R}-\text { AdaptiveCD }
\end{aligned}
$$

where $S H D H_{R}$ is the annual saving in heating degrees of heating adaptive setpoints with respect to static setpoints of $R\left[{ }^{\circ} \mathrm{C}\right]$, and $S C D H_{R}$ is the annual saving in cooling degrees of cooling adaptive setpoints with respect to static setpoints of $R\left[{ }^{\circ} \mathrm{C}\right]$.

\subsection{Cluster analysis}

One of the stages of the study analysis was to conduct a cluster analysis to identify the similarities among the Andalusian cities. For this purpose, the $k$-means algorithm was used, which is an iterative algorithm based on the centroid concept of a group of individuals [43]. This method classifies a sample $X$ of $n$ individuals into $k$ groups, for which a partition $W$ of such sample with $W=\left(w_{1}, \ldots, w_{a}, \ldots, w_{b}, \ldots, w_{k}\right)$ is considered. Therefore, $\left(\cup_{a=1}^{k} w_{a}=X, w_{a} \cap w_{b}=\emptyset, \mathrm{a} \neq \mathrm{b}\right)$, and thus, the total sum of the sums of squares of the Euclidean distances is minimum within each group:

$\underset{W}{\operatorname{argmin}} \sum_{a=1}^{k} \sum_{x_{i} \in w_{a}} \sum_{r=1}^{p}\left(x_{i r}-\mu_{a r}\right)^{2}$

This method is sensitive to initial centroids; thus, various results can be obtained by varying the initial values of $k$. In this regard, the greater the value of $k$ used in the algorithm, the lower is the variation within the groups. If the variables have different units, the data should be normalised before conducting the cluster analysis (i.e. variables are rescaled between 1 and 0 using max-min normalisation).

In this study, to select the number of groups optimally, three analyses were conducted, based on the Elbow method, silhouette index $(s(i))$, and ratio between sum of squares and total sum of square (BSS/TSS).

The Elbow method involves selecting the optimal number of $k$ by 

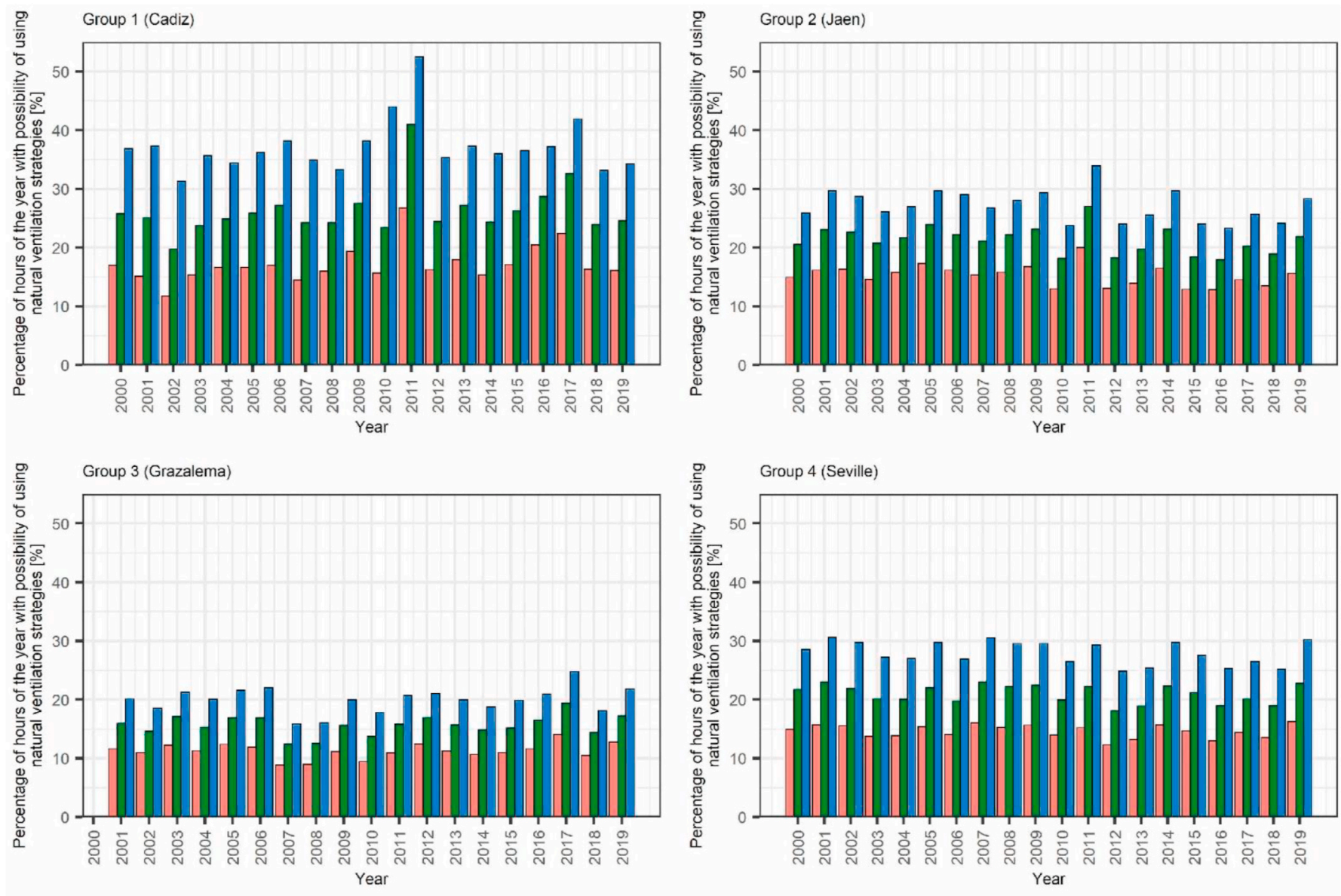

Fig. 5. Percentage of hours of the year with possibility to apply natural ventilation strategies between 2000 and 2019 .

minimising the total within-cluster sum of squares (WSS) [44]. This method involves applying the $k$-means algorithm for different values of $k$ as well as calculating WSS (Eq. (19)). The representation of the WSS curve allows the elbow of such curve, which indicates the optimal number of groups, to be determined.

$W S S=\sum_{k=1}^{K} \sum_{i \in S_{k}} \sum_{j=1}^{p}\left(x_{i j}-\bar{x}_{k j}\right)^{2}$

However, the elbow of the curve cannot always be clearly observed [44], especially in cases where there is a gradual and continuous data transition. In these cases, the method does not provide a unique possible solution but a range of possible solutions, which should be examined to determine the best value. For this reason, we combined the Elbow method with two indicators: $s(i)$ and BSS/TSS.

BSS/TSS indicates the cluster compactness, and is a percentage relation that can have values between $0 \%$ and $100 \%$. The greater the value of the ratio, the greater is the compactness of individuals within a group. The ratio is formulated as follows:

$$
\frac{B S S}{T S S}=\frac{\sum_{k=1}^{K} \sum_{j=1}^{p}\left(\bar{x}_{k j}-\bar{x}_{G}\right)^{2}}{\sum_{k=1}^{K} \sum_{j=1}^{p}\left(\bar{x}_{k j}-\bar{x}_{G}\right)^{2}+\sum_{k=1}^{K} \sum_{i \in S_{k}} \sum_{j=1}^{p}\left(x_{i j}-\bar{x}_{k j}\right)^{2}}
$$

where $\bar{x}_{G}$ is the grand mean of the means of all the groups.

Finally, $s(i)$ is among the most frequently used indices in cluster analysis [45], and indicates the similarity of an individual with the other individuals of the same group. The quality of a group is, therefore, measured. For this purpose, the following equation is used:

$s(i)=\frac{b(i)-a(i)}{\max \{a(i), b(i)\}}$

where $a(i)$ is the average distance between an individual (i) and the remaining points of the same group and $b(i)$ is the minimum average distance between the individual and the others. The $s(i)$ can have values ranging between -1 and 1 . The meaning of these values determines the suitability of the cluster analysis. (i) A value between 0 and 1 indicates that the individual is placed in the correct cluster, thus obtaining optimal values close to 1 . (ii) The value is 0 means that the individual lies between two groups, indicating that either the individual shows very different characteristics with respect to the others, thus not being able to be grouped with the others, or that the cluster analysis has excessively classified individual groups. (iii) A value between -1 and 0 indicates that the individual is placed in an incorrect cluster.

\subsection{Artificial neural network}

Another aspect to be considered within the methodological framework of this research is the need for estimating the variables of potential energy-saving described in Section 2.2. Given the difficulty in obtaining hourly data, the possibility of estimating these variables using artificial neural networks was considered. Neural networks are bio-inspired statistical models that simulate the neurological brain structure to solve regression and classification problems [46]. Among the various typologies of artificial neural networks, MLPs provide the best features owing to their capability of universal approximation [47-49]. MLPs are 

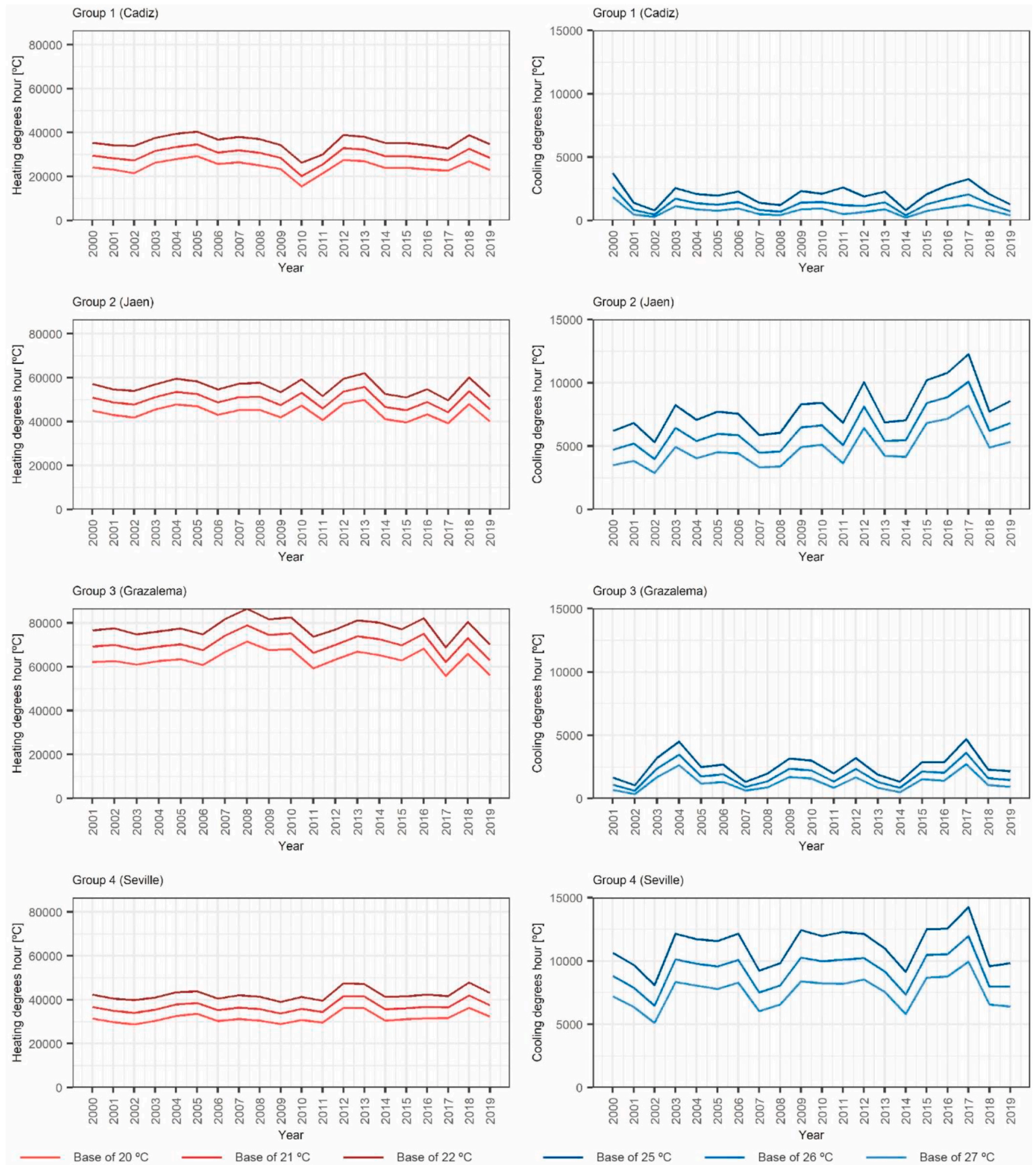

Fig. 6. Hourly heating and cooling degrees required to acclimatise the buildings of the analysis zone between the year 2000 and 2019.

characterised as presenting an architecture of three or more layers, each with a series of nodes and neurons. (i) An input layer whose nodes correspond to the different input variables considered in the model, (ii) one or several intermediate layers with interconnected nodes, and (iii) an output layer that corresponds to the output variable (or dependent variable) and whose value is obtained by summing the values of the input neurons weighted by synaptic weights and applying an activation function:
$\widehat{Y}_{M L P}=\sigma\left(\sum_{k=1}^{M} w_{l k}^{(2)} \sigma\left(\sum_{j=0}^{d} w_{k j}^{(1)} x_{j}\right)+w_{l 0}^{(2)} y_{0}\right)$

where $\widehat{Y}_{M L P}$ is the estimation performed by the MLP, $x_{j}$ indicates the values of the input layer, $w_{k 0}^{(1)}$ and $x_{0}$ are the weight and input value of the bias neuron of the input layer, respectively, $w_{k j}^{(1)}$ indicates the 

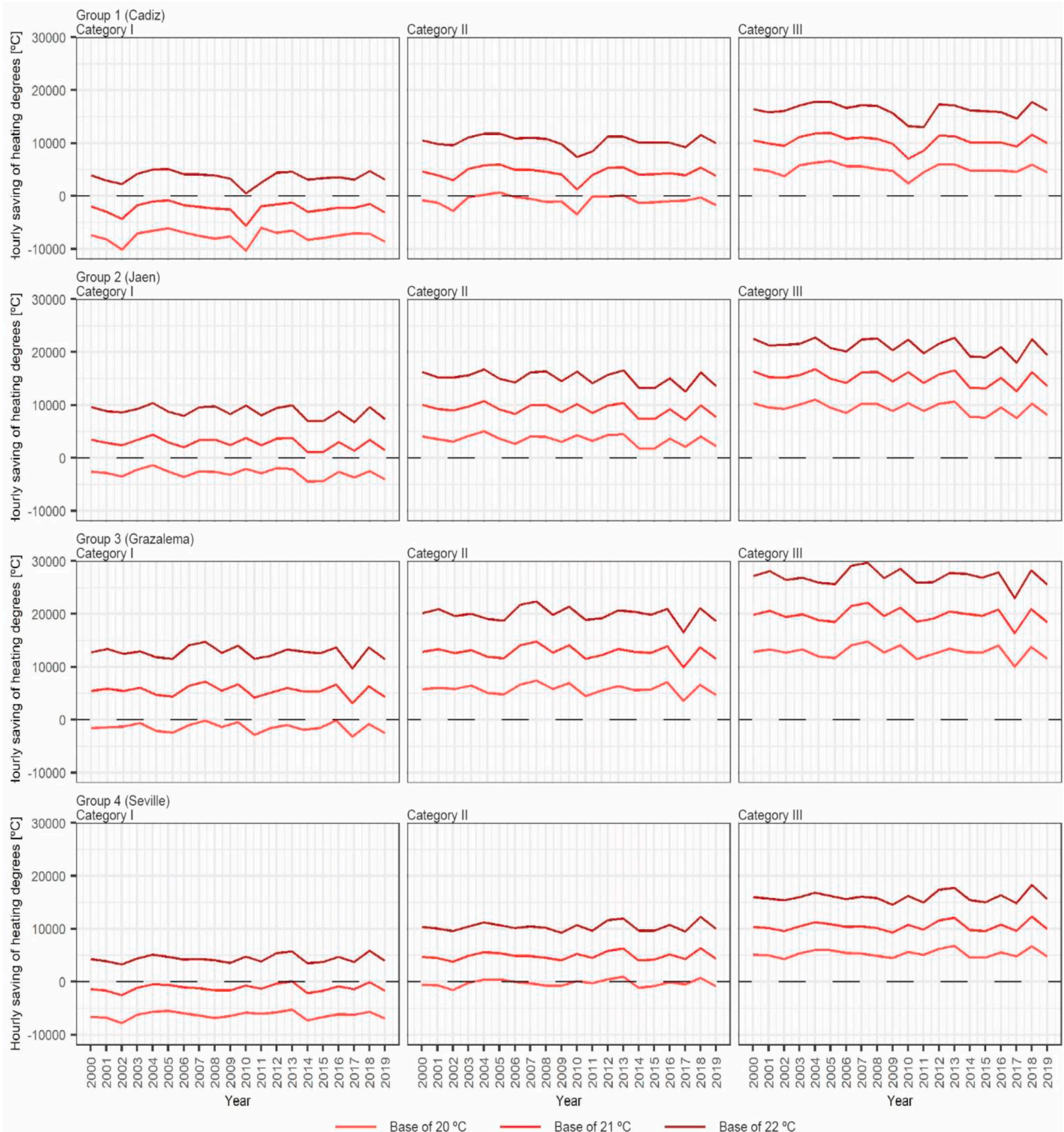

Fig. 7. Saving of hourly heating degrees by using adaptive setpoint temperatures between 2000 and 2019 .

weights of the hidden layer, $w_{l 0}^{(2)}$ and $y_{0}$ are the weight and input value of the bias neuron of the hidden layer, $w_{l k}^{(2)}$ indicates the weights of the output layer, $y_{k}$ is the output value of a neuron of the hidden layer, and $\sigma$ is the activation function. In this study, models with a hidden layer were considered, and a sigmoidal activation function was considered in both the hidden and output layers (Eq. (23)), similarly to the case of other studies in which these models were applied [50], as they usually perform better than those in more complex structures [51]. The number of nodes of the hidden layer is determined by Eq. (24). $\sigma=\frac{1}{1+e^{-x}}$

Number of nodes $=\frac{N I+N O}{2}$

where $N I$ is the number of nodes of the input layer (i.e. the input variables of the dataset) and $N O$ is that of the output layer (i.e. the output variables of the dataset).

As indicated above, the output value is obtained from the weighted 


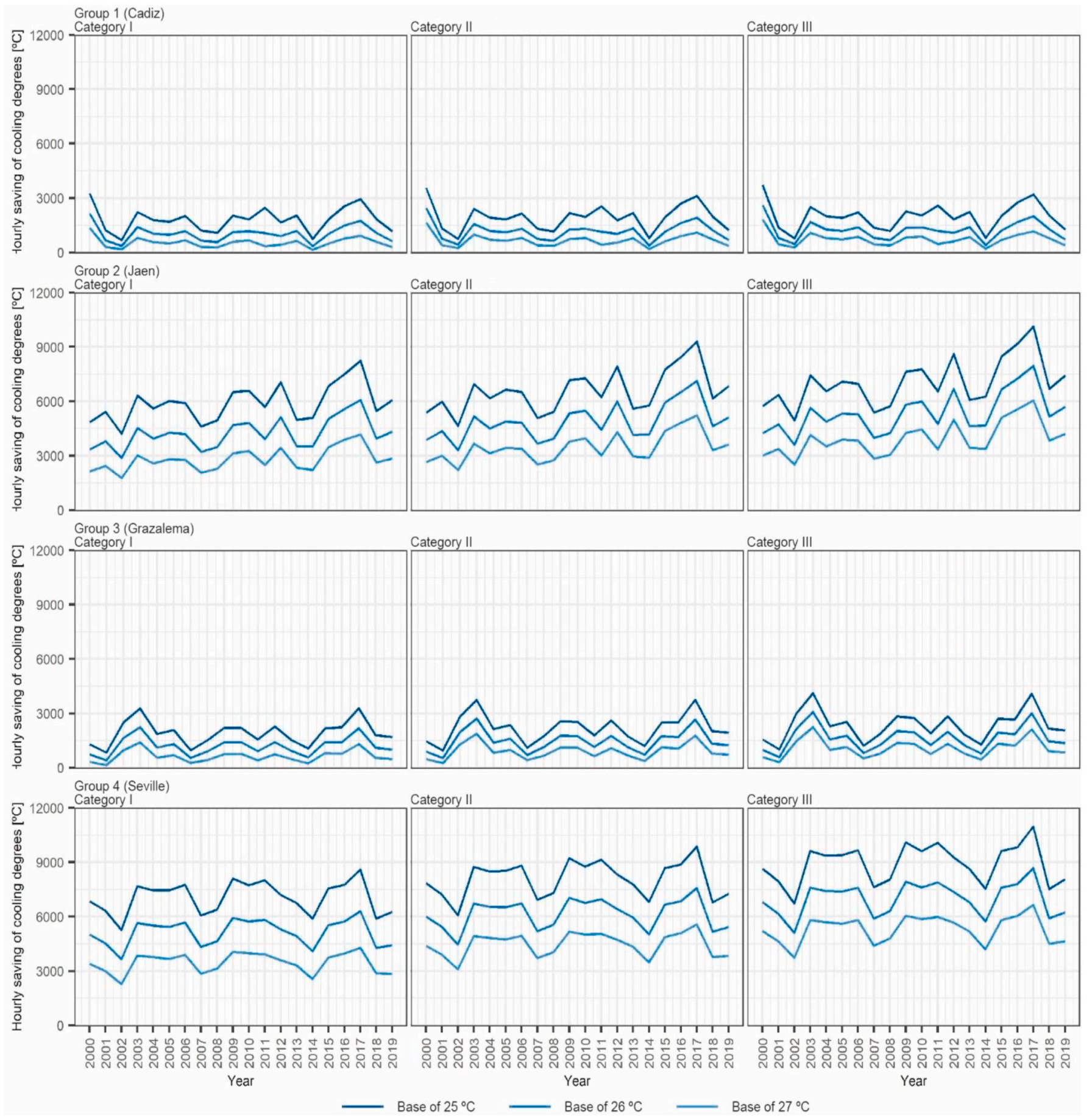

Fig. 8. Saving of hourly cooling degrees by using adaptive setpoint temperatures between 2000 and 2019 .

propagation of the input signs. One of the most important aspects of MLPs is, therefore, the adjustment of synaptic weights for reducing the error between the estimated and actual values. For this purpose, the models were trained through backpropagation [52-54] by using the Broyden-Fletcher-Goldfarb-Shanno [55] algorithm (which belongs to quasi-Newton methods). Three statistical parameters were used to assess the model performance: (i) determination coefficient $\left(R^{2}\right)$ (Eq. (25)), root mean square error (RMSE) (Eq. (26)), and mean absolute error (MAE) (Eq. (27)). The use of these parameters allowed the model performance to be appropriately defined.

$$
\begin{aligned}
& R^{2}=100\left(1-\frac{\sum_{i=1}^{n}\left(t_{i}-m_{i}\right)^{2}}{\sum_{i=1}^{n}\left(t_{i}-\bar{t}_{i}\right)^{2}}\right) \\
& R M S E=\left(\frac{\sum_{i=1}^{n}\left(t_{i}-m_{i}\right)^{2}}{n}\right)^{1 / 2} \\
& M A E=\frac{\sum_{i=1}^{n}\left|t_{i}-m_{i}\right|}{n}
\end{aligned}
$$

where $t_{i}$ is the actual value, $m_{i}$ is the model's prediction, and $n$ is the 
Table 4

Input and output variables configured in each MLP used in the study.

\begin{tabular}{|c|c|c|c|c|c|c|}
\hline Input variables & Outpu & ariable & & & & \\
\hline $\begin{array}{l}\bar{T}_{\text {January }}, \bar{T}_{\text {January-min }}, \\
\bar{T}_{\text {January-max }}, \\
\bar{T}_{\text {February }}, \bar{T}_{\text {February-min }}, \\
\bar{T}_{\text {February-max, }} \\
\bar{T}_{\text {March }}, \bar{T}_{\text {March-min }}, \\
\bar{T}_{\text {March-max }}, \\
\bar{T}_{\text {April }}, \bar{T}_{\text {April-min }}, \bar{T}_{\text {April-max }}, \\
\bar{T}_{\text {May }}, \bar{T}_{\text {May-min }}, \bar{T}_{\text {May-max }}, \\
\bar{T}_{\text {June }}, \bar{T}_{\text {June-min }}, \bar{T}_{\text {June-max }}, \\
\bar{T}_{\text {July }}, \bar{T}_{\text {July-min }}, \bar{T}_{\text {July-max }}, \\
\bar{T}_{\text {August }}, \bar{T}_{\text {August-min }}, \\
\bar{T}_{\text {August-max }}, \\
\bar{T}_{\text {September }}, \bar{T}_{\text {September-min }}, \\
\bar{T}_{\text {September-max }}, \\
\bar{T}_{\text {October }}, \bar{T}_{\text {October-min }}, \\
\bar{T}_{\text {October-max }}, \\
\bar{T}_{\text {November }}, \bar{T}_{\text {November-min }}, \\
\bar{T}_{\text {November-max }}, \\
\bar{T}_{\text {December }}, \bar{T}_{\text {December-min }}, \\
\bar{T}_{\text {December-max }}\end{array}$ & $\begin{array}{l}\text { MLP- } \\
01 \\
\text { MLP- } \\
04 \\
\text { MLP- } \\
07 \\
\text { MLP- } \\
10 \\
\text { MLP- } \\
13 \\
\text { MLP- } \\
16 \\
\text { MLP- } \\
19 \\
\text { MLP- } \\
22 \\
\text { MLP- } \\
25\end{array}$ & $\begin{array}{l}\text { Hourly cooling degrees }\left(25^{\circ} \mathrm{C} \text { ) }\right. \\
\text { Percentage of hours of natural } \\
\text { ventilation (category I) } \\
\text { Hourly heating degrees (category I - } \\
20^{\circ} \mathrm{C} \text { ) } \\
\text { Hourly cooling degrees (category I - } \\
25^{\circ} \mathrm{C} \text { ) } \\
\text { Hourly heating degrees (category II } \\
-20^{\circ} \mathrm{C} \text { ) } \\
\text { Hourly cooling degrees (category II - } \\
25^{\circ} \mathrm{C} \text { ) } \\
\text { Hourly heating degrees (category III } \\
-20^{\circ} \mathrm{C} \text { ) } \\
\text { Hourly cooling degrees (category III } \\
-25^{\circ} \mathrm{C} \text { ) }\end{array}$ & $\begin{array}{l}\text { MLP- } \\
02 \\
\text { MLP- } \\
05 \\
\text { MLP- } \\
08 \\
\text { MLP- } \\
11 \\
\text { MLP- } \\
14 \\
\text { MLP- } \\
17 \\
\text { MLP- } \\
20 \\
\text { MLP- } \\
23 \\
\text { MLP- } \\
26\end{array}$ & $\begin{array}{l}\text { Percentage of hours of natural } \\
\text { ventilation (category II) } \\
\text { Hourly heating degrees (category I - } \\
21^{\circ} \mathrm{C} \text { ) } \\
\text { Hourly cooling degrees (category I - } \\
26^{\circ} \mathrm{C} \text { ) } \\
\text { Hourly heating degrees (category II - } \\
21^{\circ} \mathrm{C} \text { ) } \\
\text { Hourly cooling degrees (category II - } \\
26^{\circ} \mathrm{C} \text { ) } \\
\text { Hourly heating degrees (category III } \\
-21^{\circ} \mathrm{C} \text { ) } \\
\text { Hourly cooling degrees (category III } \\
-26^{\circ} \mathrm{C} \text { ) }\end{array}$ & $\begin{array}{l}\text { MLP- } \\
03 \\
\text { MLP- } \\
06 \\
\text { MLP- } \\
09 \\
\text { MLP- } \\
12 \\
\text { MLP- } \\
15 \\
\text { MLP- } \\
18 \\
\text { MLP- } \\
21 \\
\text { MLP- } \\
24 \\
\text { MLP- } \\
27\end{array}$ & $\begin{array}{l}\text { Percentage of hours of natural } \\
\text { ventilation (category III) } \\
\text { Hourly heating degrees (category I - } \\
22{ }^{\circ} \mathrm{C} \text { ) } \\
\text { Hourly cooling degrees (category I - } \\
27^{\circ} \mathrm{C} \text { ) } \\
\text { Hourly heating degrees (category II - } \\
22^{\circ} \mathrm{C} \text { ) } \\
\text { Hourly cooling degrees (category II - } \\
27{ }^{\circ} \mathrm{C} \text { ) } \\
\text { Hourly heating degrees (category III } \\
-22^{\circ} \mathrm{C} \text { ) } \\
\text { Hourly cooling degrees (category III - } \\
27{ }^{\circ} \mathrm{C} \text { ) }\end{array}$ \\
\hline
\end{tabular}

number of instances in the dataset.

\subsection{Climate data}

A cluster analysis of the existing climates in the region of Andalusia was performed. Given the difficulties in achieving the recent temperature records, this analysis simplified the procedure. For this purpose, climate data from the 786 Andalusian municipalities were obtained with METEONORM, which is a climate file database comprising 8325 weather stations spread throughout the planet and has been widely used in various studies [56-59]. Based on the data of seasons, hourly external temperature values were obtained by using a stochastic model [60]. The temperature period generated was 2000-2009, and the radiation period was 1991-2010. After generating the hourly time series of the 786 Andalusian municipalities, the data were treated for generating the dataset used in the cluster analysis. From this analysis (which is detailed in the Results section), four climate clusters were detected in the Andalusia region, each of which selected a representative city from which recent temperature data were available. The chosen cities were as follows: Cadiz for cluster 1, Jaen for cluster 2, Grazalema for cluster 3, and Seville for cluster 4. The temperature data were obtained from the automatic weather stations of the State Meteorological Agency in Spain. Note that the types of temperature data and available dates varied in each municipality. Likewise, the time series were validated by the State Meteorological Agency in Spain. Table 1 indicates the types of temperature variables available and their time period. For most cities, hourly temperature data between 2000 and 2019 were available (except Grazalema, whose data were available from 2001), whereas data from the 20 th century were available at a daily scale (in terms of average, maximum, and minimum values) and with a range of dates that varied according to the city analysed. As for Grazalema, data from the 20th century were not available, indicating a lack of monitoring data in the cities at a huge altitude in the Andalusian territory. Table 2 indicates the technical specifications of the probes of each weather station.

\section{Results and discussion}

\subsection{Climate classification}

First, a cluster analysis of the existing climates in Andalusia was conducted. Owing to the difficulties in obtaining the recent temperature records, this analysis simplified the procedure. Following the analysis procedure described in Section 2.2., a dataset was generated, in which each instance was one of the municipalities and the variables were those of potential energy-saving with adaptive strategies (i.e. percentage of application, percentage of ventilation (by category), and saving of heating and cooling degrees (by category and a different static setpoint temperature)). Thus, it was a multi-dimensional cluster analysis. The following step involved determining the optimal number of $k$ for the classification. For this purpose, the elbow method and the analysis of both $s(i)$ and BSS/TSS were used. For a simplified discussion of the results, Fig. 1 summarises the results obtained in the cluster analysis. The results showed that $k=4$ yielded the best cluster. This aspect can be observed for the average values of the silhouette index, as the highest value was obtained at 4 , whereas the remaining clusters obtained lower values. In addition, BSS/TSS obtained a value of $82.7 \%$, constituting an increase of $12.9 \%$ with respect to $k=3$, thus showing the use of $k=4$.

The Andalusian cities can, therefore, be divided into four clusters according to the potential of the adaptive strategies, reflecting the geographic characteristics:

- Cluster 1 corresponds to municipalities whose cities are located on the coast. In this regard, the municipalities included in Fig. 1 are close to the coast but belong to another cluster as the city is far from the coast.

- Cluster 2 corresponds to municipalities located in mountain systems, such as Sierra Morena and the Subbaetic System.

- Cluster 3 corresponds to cities whose vast majority are located in the highest-altitude areas of the Baetic Mountain Ranges (e.g. Sierra Nevada), while the remaining are located at a great altitude above the sea level.

- Cluster 4 corresponds to the depression of the Guadalquivir River.

Consequently, an aspect was found in the overall study [34], as climate classification of the potential application of adaptive strategies could be conducted according to the existing geographic characteristics of each region. Cluster 2 corresponds to a heterogeneous zone that could not be related to any geographic element.

Furthermore, the clusters do not coincide with the climatic zones established in the Spanish Building Technical Code [42], which classifies the climate according to the winter and summer climate severity. For winter, the code assigns letters ranging from A (slightly cold weather) to E (very cold weather), while for summer, it assigns numbers ranging from 1 (not very hot weather) to 4 (very hot weather). As shown in 
Table 5

Results obtained in the statistical parameters during the testing phase.

\begin{tabular}{|c|c|c|c|c|}
\hline \multirow[t]{2}{*}{ Model } & \multirow[t]{2}{*}{ Output variable } & \multicolumn{3}{|l|}{ Testing } \\
\hline & & $R^{2}$ & $M A E$ & RMSE \\
\hline $\begin{array}{c}\text { MLP- } \\
01\end{array}$ & Hourly heating degrees $\left(20^{\circ} \mathrm{C}\right)$ & 99.77 & 290.93 & 913.16 \\
\hline $\begin{array}{c}\text { MLP- } \\
02\end{array}$ & Hourly heating degrees $\left(21^{\circ} \mathrm{C}\right)$ & 99.70 & 397.48 & 1120.66 \\
\hline $\begin{array}{c}\text { MLP- } \\
03\end{array}$ & Hourly heating degrees $\left(22^{\circ} \mathrm{C}\right)$ & 99.72 & 338.44 & 1034.20 \\
\hline $\begin{array}{c}\text { MLP- } \\
04\end{array}$ & Hourly cooling degrees $\left(25^{\circ} \mathrm{C}\right)$ & 99.59 & 144.40 & 232.59 \\
\hline $\begin{array}{l}\text { MLP- } \\
05\end{array}$ & Hourly cooling degrees $\left(26^{\circ} \mathrm{C}\right)$ & 99.63 & 158.81 & 254.31 \\
\hline $\begin{array}{l}\text { MLP- } \\
06\end{array}$ & Hourly cooling degrees $\left(27^{\circ} \mathrm{C}\right)$ & 99.68 & 116.08 & 177.85 \\
\hline $\begin{array}{c}\text { MLP- } \\
07\end{array}$ & $\begin{array}{l}\text { Percentage of hours of natural } \\
\text { ventilation (category I) }\end{array}$ & 95.20 & 0.46 & 0.78 \\
\hline $\begin{array}{c}\text { MLP- } \\
08\end{array}$ & $\begin{array}{l}\text { Percentage of hours of natural } \\
\text { ventilation (category II) }\end{array}$ & 92.35 & 0.73 & 1.42 \\
\hline $\begin{array}{c}\text { MLP- } \\
09\end{array}$ & $\begin{array}{l}\text { Percentage of hours of natural } \\
\text { ventilation (category III) }\end{array}$ & 93.51 & 0.69 & 1.73 \\
\hline $\begin{array}{l}\text { MLP- } \\
10\end{array}$ & $\begin{array}{l}\text { Hourly heating degrees (category I - } \\
20^{\circ} \mathrm{C} \text { ) }\end{array}$ & 86.86 & 156.59 & 938.93 \\
\hline $\begin{array}{l}\text { MLP- } \\
11\end{array}$ & $\begin{array}{l}\text { Hourly heating degrees (category I - } \\
21^{\circ} \mathrm{C} \text { ) }\end{array}$ & 94.26 & 130.31 & 959.20 \\
\hline $\begin{array}{l}\text { MLP- } \\
12\end{array}$ & $\begin{array}{l}\text { Hourly heating degrees (category I - } \\
22^{\circ} \mathrm{C} \text { ) }\end{array}$ & 89.99 & 137.11 & 1047.54 \\
\hline $\begin{array}{l}\text { MLP- } \\
13\end{array}$ & $\begin{array}{l}\text { Hourly cooling degrees (category I - } \\
25^{\circ} \mathrm{C} \text { ) }\end{array}$ & 99.64 & 77.31 & 118.90 \\
\hline $\begin{array}{l}\text { MLP- } \\
14\end{array}$ & $\begin{array}{l}\text { Hourly cooling degrees (category I - } \\
26^{\circ} \mathrm{C} \text { ) }\end{array}$ & 99.76 & 86.53 & 129.38 \\
\hline $\begin{array}{l}\text { MLP- } \\
15\end{array}$ & $\begin{array}{l}\text { Hourly cooling degrees (category I - } \\
27^{\circ} \mathrm{C} \text { ) }\end{array}$ & 99.68 & 50.14 & 81.15 \\
\hline $\begin{array}{l}\text { MLP- } \\
16\end{array}$ & $\begin{array}{l}\text { Hourly heating degrees (category II - } \\
20^{\circ} \mathrm{C} \text { ) }\end{array}$ & 91.20 & 125.77 & 906.49 \\
\hline $\begin{array}{l}\text { MLP- } \\
17\end{array}$ & $\begin{array}{l}\text { Hourly heating degrees (category II - } \\
21^{\circ} \mathrm{C} \text { ) }\end{array}$ & 96.73 & 155.29 & 827.82 \\
\hline $\begin{array}{c}\text { MLP- } \\
18\end{array}$ & $\begin{array}{l}\text { Hourly heating degrees (category II - } \\
22{ }^{\circ} \mathrm{C} \text { ) }\end{array}$ & 93.92 & 125.52 & 945.51 \\
\hline $\begin{array}{l}\text { MLP- } \\
19\end{array}$ & $\begin{array}{l}\text { Hourly cooling degrees (category II - } \\
25^{\circ} \mathrm{C} \text { ) }\end{array}$ & 99.66 & 87.86 & 135.87 \\
\hline $\begin{array}{l}\text { MLP- } \\
20\end{array}$ & $\begin{array}{l}\text { Hourly cooling degrees (category II - } \\
26^{\circ} \mathrm{C} \text { ) }\end{array}$ & 99.76 & 100.96 & 148.48 \\
\hline $\begin{array}{l}\text { MLP- } \\
21\end{array}$ & $\begin{array}{l}\text { Hourly cooling degrees (category II - } \\
27^{\circ} \mathrm{C} \text { ) }\end{array}$ & 99.73 & 62.87 & 95.35 \\
\hline $\begin{array}{l}\text { MLP- } \\
22\end{array}$ & $\begin{array}{l}\text { Hourly heating degrees (category III - } \\
20^{\circ} \mathrm{C} \text { ) }\end{array}$ & 94.41 & 132.25 & 877.20 \\
\hline $\begin{array}{l}\text { MLP- } \\
23\end{array}$ & $\begin{array}{l}\text { Hourly heating degrees (category III - } \\
21^{\circ} \mathrm{C} \text { ) }\end{array}$ & 97.45 & 219.75 & 842.25 \\
\hline $\begin{array}{l}\text { MLP- } \\
24\end{array}$ & $\begin{array}{l}\text { Hourly heating degrees (category III - } \\
22^{\circ} \mathrm{C} \text { ) }\end{array}$ & 96.42 & 165.53 & 856.21 \\
\hline $\begin{array}{c}\text { MLP- } \\
25\end{array}$ & $\begin{array}{l}\text { Hourly cooling degrees (category III - } \\
25^{\circ} \mathrm{C} \text { ) }\end{array}$ & 99.69 & 97.68 & 149.05 \\
\hline $\begin{array}{l}\text { MLP- } \\
26\end{array}$ & $\begin{array}{l}\text { Hourly cooling degrees (category III - } \\
26^{\circ} \mathrm{C} \text { ) }\end{array}$ & 99.71 & 117.84 & 177.25 \\
\hline $\begin{array}{l}\text { MLP- } \\
27\end{array}$ & $\begin{array}{l}\text { Hourly cooling degrees (category III - } \\
27^{\circ} \mathrm{C} \text { ) }\end{array}$ & 99.70 & 75.25 & 117.47 \\
\hline
\end{tabular}

Fig. 2, the clusters presented different climatic zones. However, certain trends were detected in the majority percentages of these zones. For example, cluster 3 grouped the most severe climatic zones in winter (D2, D3, and E1), while cluster 1 grouped those with less severity (A3 and A4). Therefore, although the climatic zones of the Spanish Building Technical Code do not fit the clusters of the adaptive model, certain zones tend to fit a given cluster. In any case, the climatic zones of the Spanish Building Technical Code would not serve to be able to perform climatic classifications of the application of adaptive models.

Note that the cluster analysis was conducted with variables obtained from the application of adaptive strategies according to the climate of each city. Each cluster, therefore, included cities with various characteristics of populations and incomes of family units. These parameters are crucial to be controlled as the main potential of these strategies lies in the acclimatisation of indoor spaces of buildings with low energy consumption. It is, therefore, vital to be able to apply adaptive strategies in cities with low income per person or family unit, with the aim of reducing the cases of energy poverty. For these reasons, the data distributions of people and incomes were assessed in each cluster (Fig. 3 and Table 3). The data were obtained from the Spanish Institute of Statistics [61,62]. The analysis results showed that cluster 1 compiled the maximum population, followed by cluster 4 . The other two clusters, in most cases, corresponded to cities with a low population density. As for the incomes, the following two aspects were observed: (i) regarding per person income, cluster 1 was characterised by clustering the lower incomes by person, whereas the other clusters obtained different values, and (ii) the incomes per household showed that clusters 2 and 3 obtained lower income values than the other two clusters. This aspect shows the complexity of the assessment of users' economic incomes, as the size of a family unit can influence the economic incomes of dwelling users. Nonetheless, this analysis reflects how, for the two income typologies, all clusters presented a potential of using adaptive strategies due to the low incomes of users and households.

\subsection{Application of adaptive strategies in the XXI century}

The first step towards analysing the application of adaptive strategies with actual data from the four clusters is the use of hourly data available. The analysis first assessed the potential application of adaptive thermal comfort models. As indicated in Subsection 2.2., the application requirement was that the external temperature should be between the lower $\left(10^{\circ} \mathrm{C}\right)$ and upper limits $\left(30^{\circ} \mathrm{C}\right)$. Fig. 4 summarises the application potential data. As could be verified, the application possibilities varied according to the cluster. Cluster 1 presented almost $100 \%$ application of the days between years 2000 and 2019, while the other clusters presented lower percentages. In this regard, cluster 4 obtained a greater percentage of application (between $81.4 \%$ and $99.2 \%$ ), cluster 2 obtained slightly lower percentages (between $68.5 \%$ and $85.5 \%$ ), and cluster 3 presented the lowest percentage (between $49.9 \%$ and $69 \%$ ). These variations in the percentages of application resulted from temperatures below $10{ }^{\circ} \mathrm{C}$ (cold days) and above $30{ }^{\circ} \mathrm{C}$ (hot days). In general, these variations varied according to the cluster: while the percentage of no application in cluster 3 resulted from the average temperature being below $10{ }^{\circ} \mathrm{C}$, there were both cold and hot days in clusters 2 and 4, with more cold days in Jaen than in Seville.

After analysing the possibilities of applying the adaptive thermal comfort models, those of natural ventilation were assessed (Fig. 5). As indicated in Section 2.2., the analysis was performed considering the percentage of yearly hours for which the outside temperature was within the limits of the comfort categories of the EN 16798-1:2019 model. This ensured that natural ventilation provided acceptable thermal comfort and reduced the use of HVAC systems. The possibilities of using the ventilation strategies never exceeded $60 \%$. In general, the trends of applying natural ventilation strategies were similar over the years and had differences among clusters. Cluster 1 obtained the greatest percentages of application (with average values of $17 \%, 26 \%$, and $37 \%$ for categories I, II, and III, respectively), whereas cluster 3 obtained the lowest percentage. As for clusters 2 and 4, the application percentages were similar. Likewise, the effect of increase in users' thermal expectations and the possibilities of natural ventilation varied according to the cluster. In cluster 1 , the increase in the category implied an average increase of between $8 \%$ and $11.6 \%$ in the possibilities of natural ventilation, whereas in the other clusters, there were average increases of between $3 \%$ and $6.7 \%$.

These results showed the possibility of applying natural ventilation strategies at more than $10 \%$ of the hours of the year, varying according to users' thermal expectations. Thus, there is a potential application of these strategies to acclimatise indoor spaces. Nonetheless, the use of HVAC systems is required to guarantee appropriate internal temperature conditions. Given this circumstance, the application of adaptive setpoint temperatures would ensure an appropriate use of HVAC systems. For 

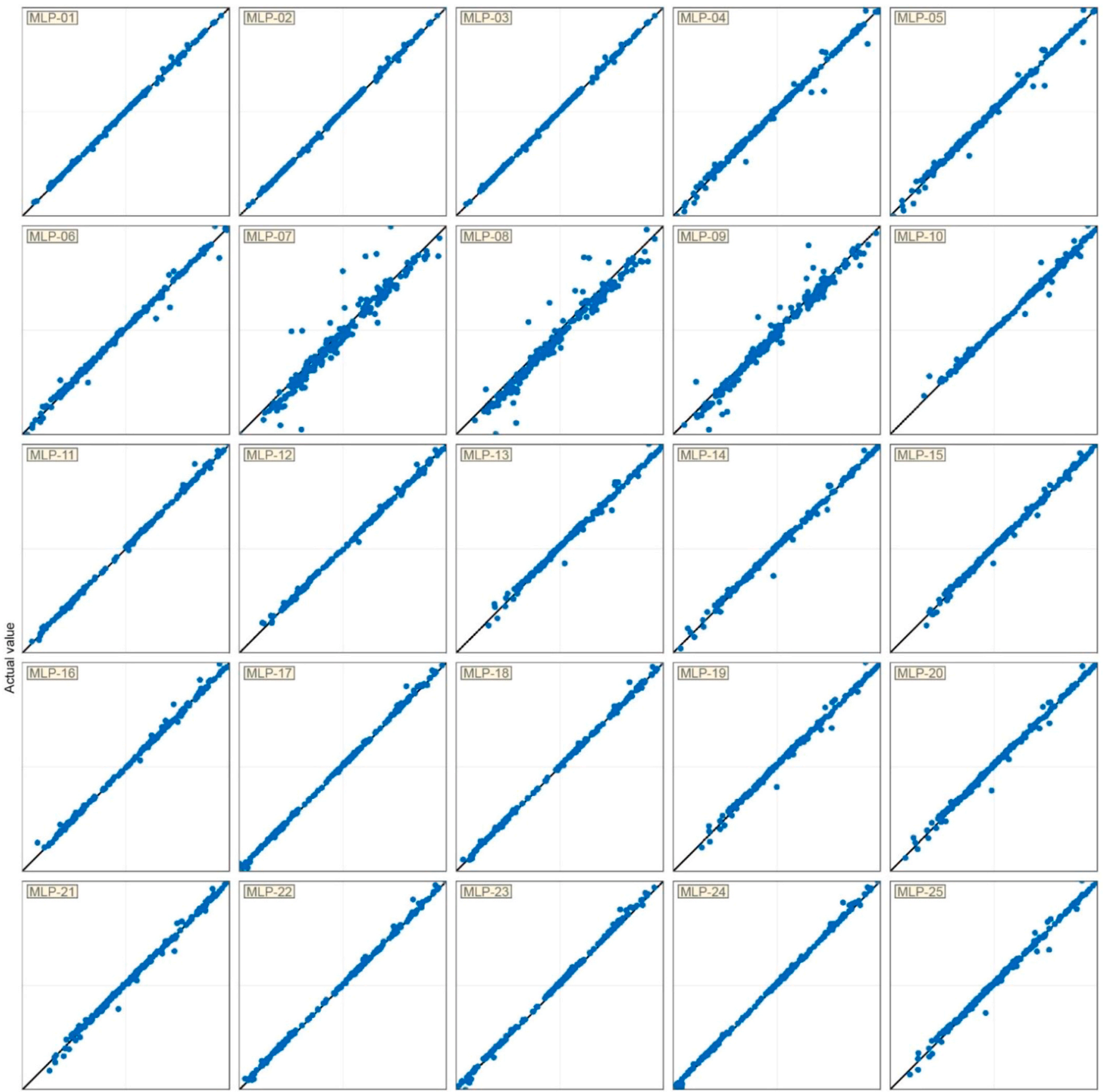

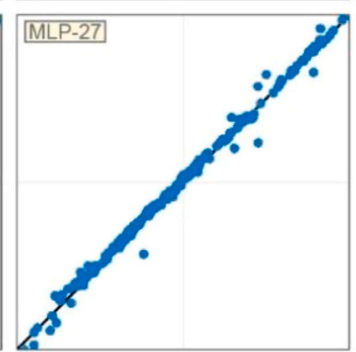

Predicted value

Fig. 9. Point clouds between the actual and estimated values per each MLP designed in the research.

this reason, the heating and cooling temperature degrees required for acclimatising the indoor spaces were first analysed, using the static setpoint temperatures defined in Subsection 2.2. Fig. 6 represents the time series of heating and cooling degrees required. As seen, each region presented certain needs of heating and cooling degrees in accordance with those reflected in Fig. 4. Thus, the zones with a $t_{r m}$ value below $10{ }^{\circ} \mathrm{C}$ were characterised as presenting heating degrees, whereas if the temperature of $30{ }^{\circ} \mathrm{C}$ was not overcome, the values of the cooling 

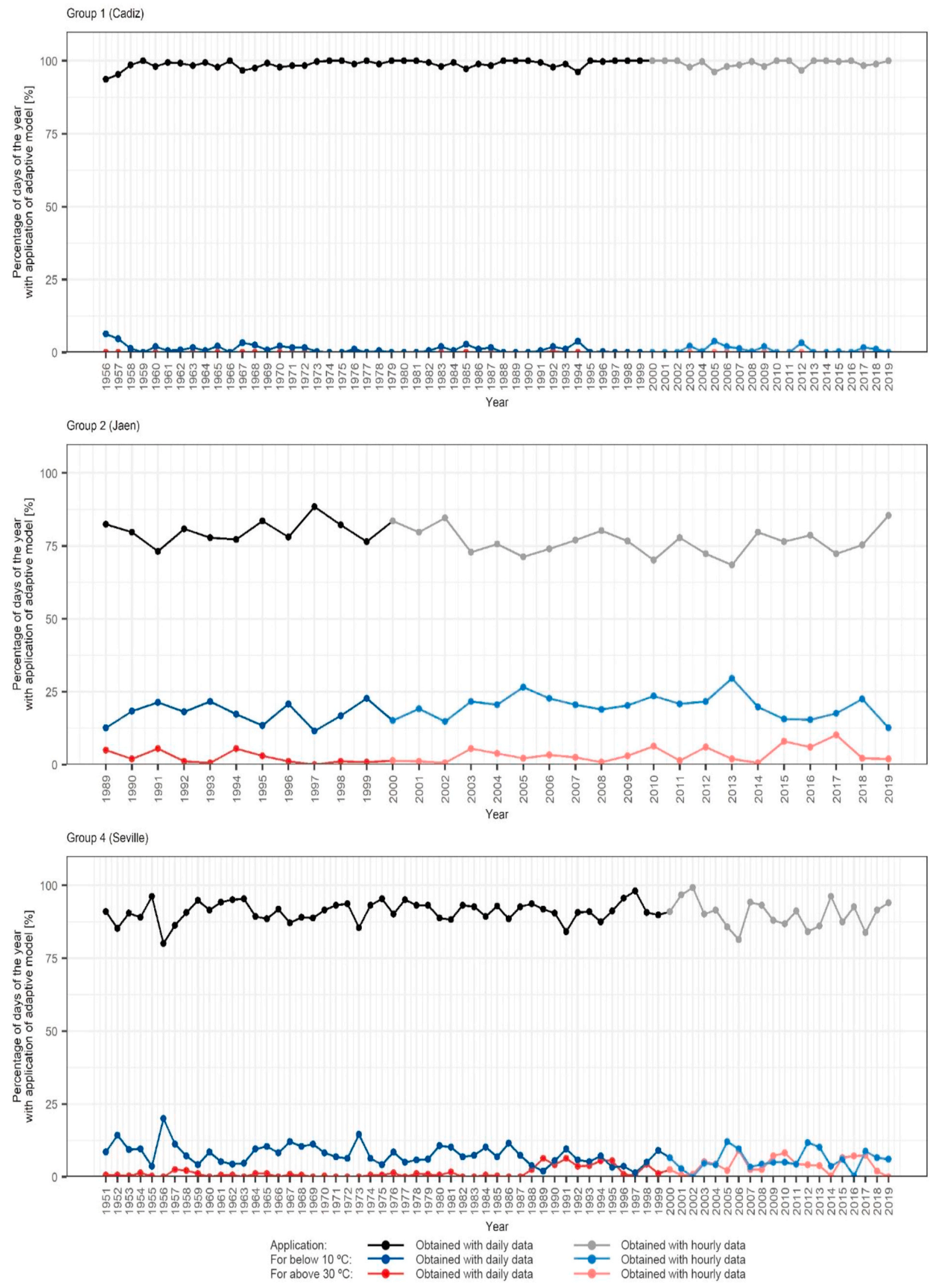

Fig. 10. Time series increased by the possibilities of application of the adaptive thermal comfort model of EN 16798-1:2019 in the period between the oldest year available for clusters and 2019. The results before the year 2000 were obtained through the existing daily mean temperature data. 
Group 1 (Cadiz)

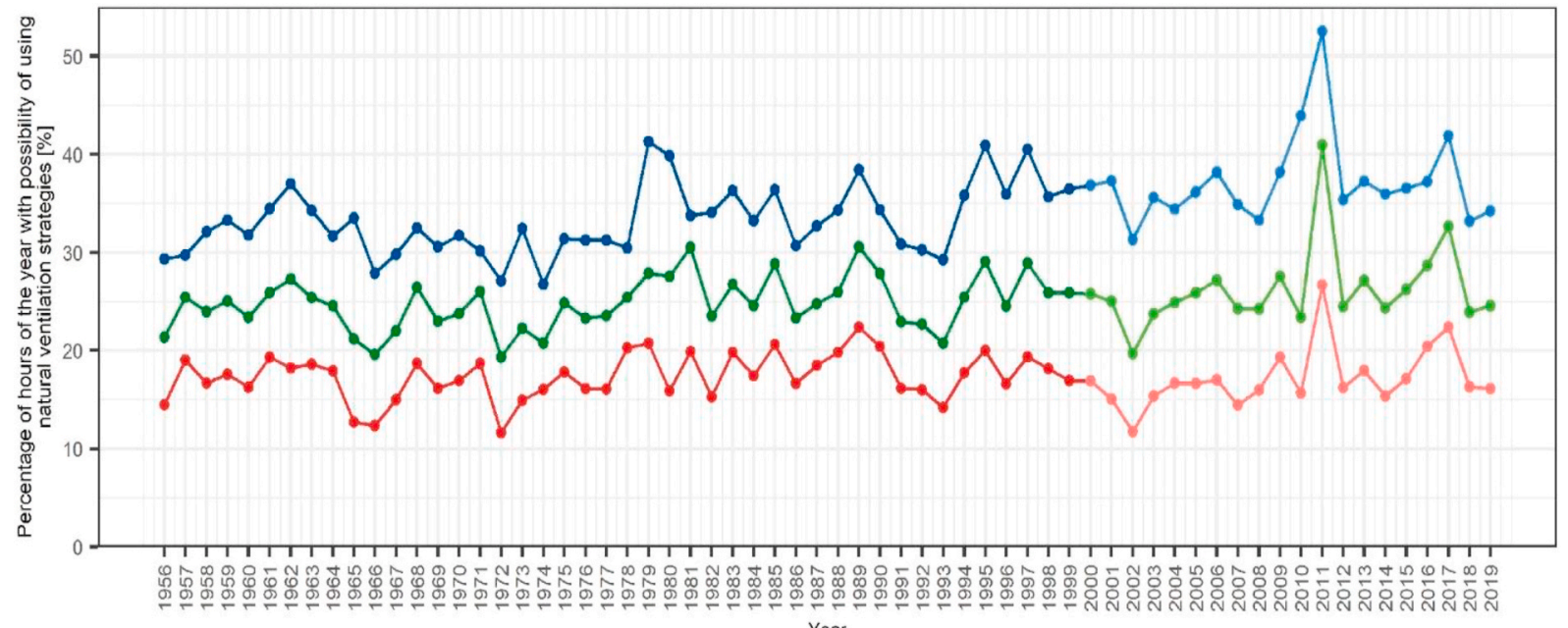

Group 2 (Jaen)

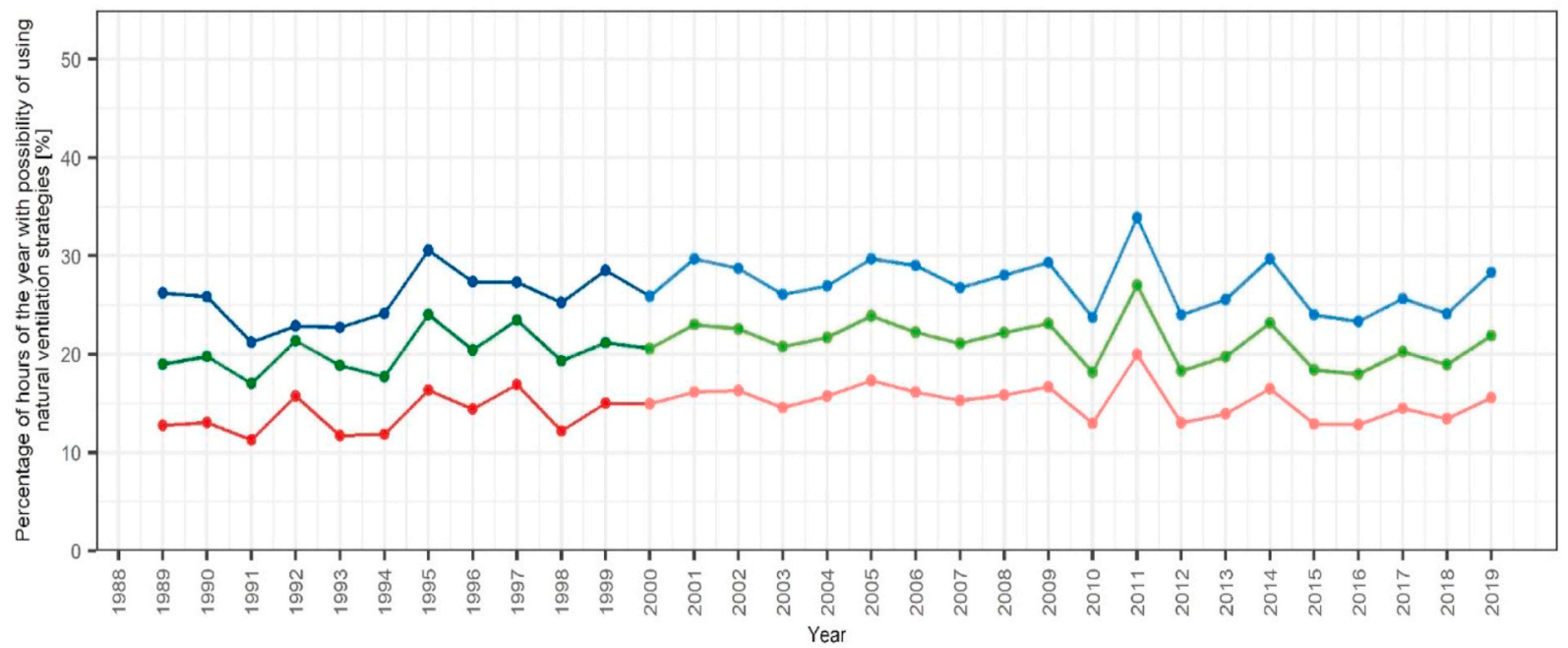

Group 4 (Seville)

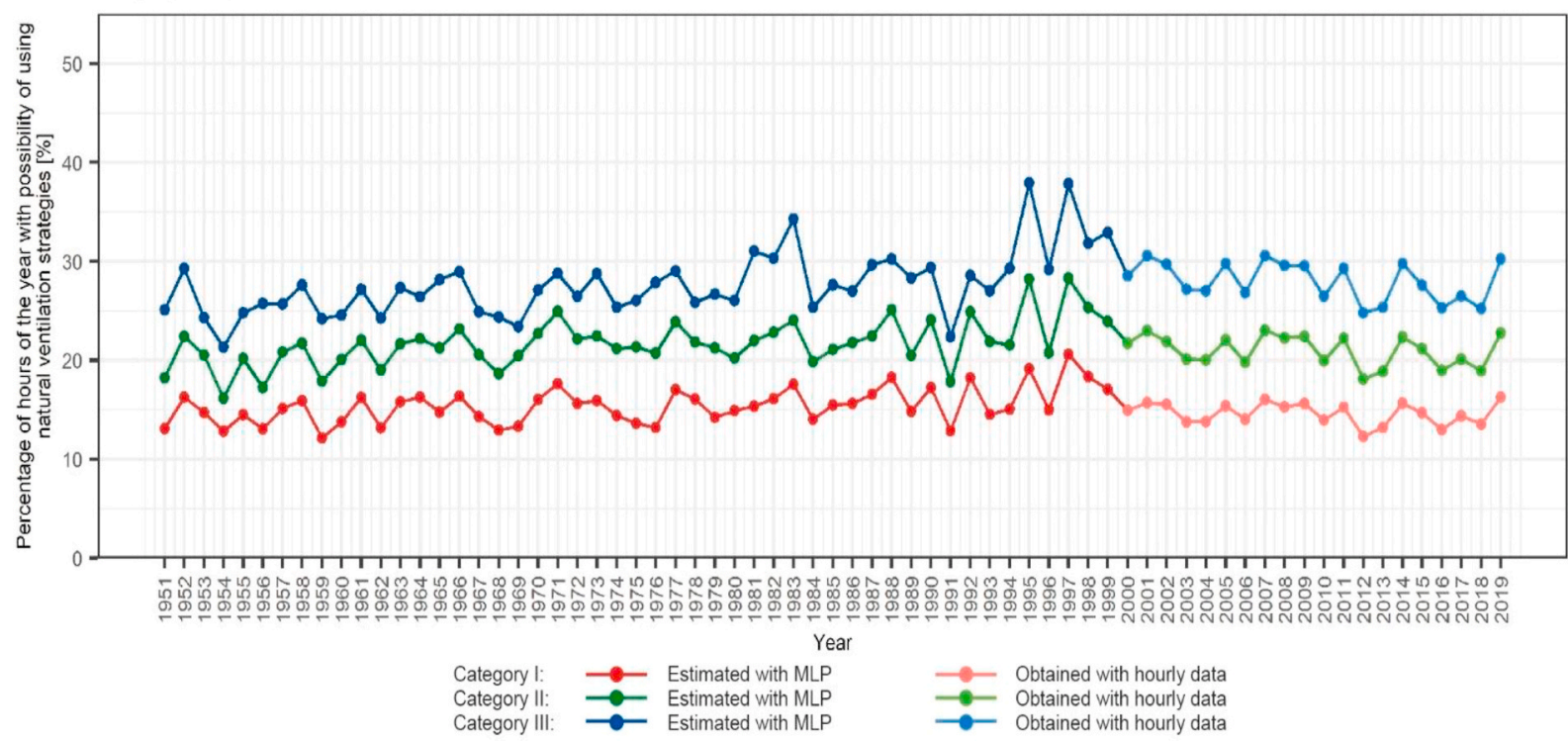

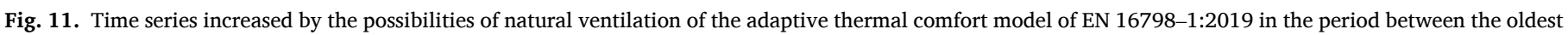
year available for clusters and 2019. The results before the year 2000 were obtained through the MLPs. 

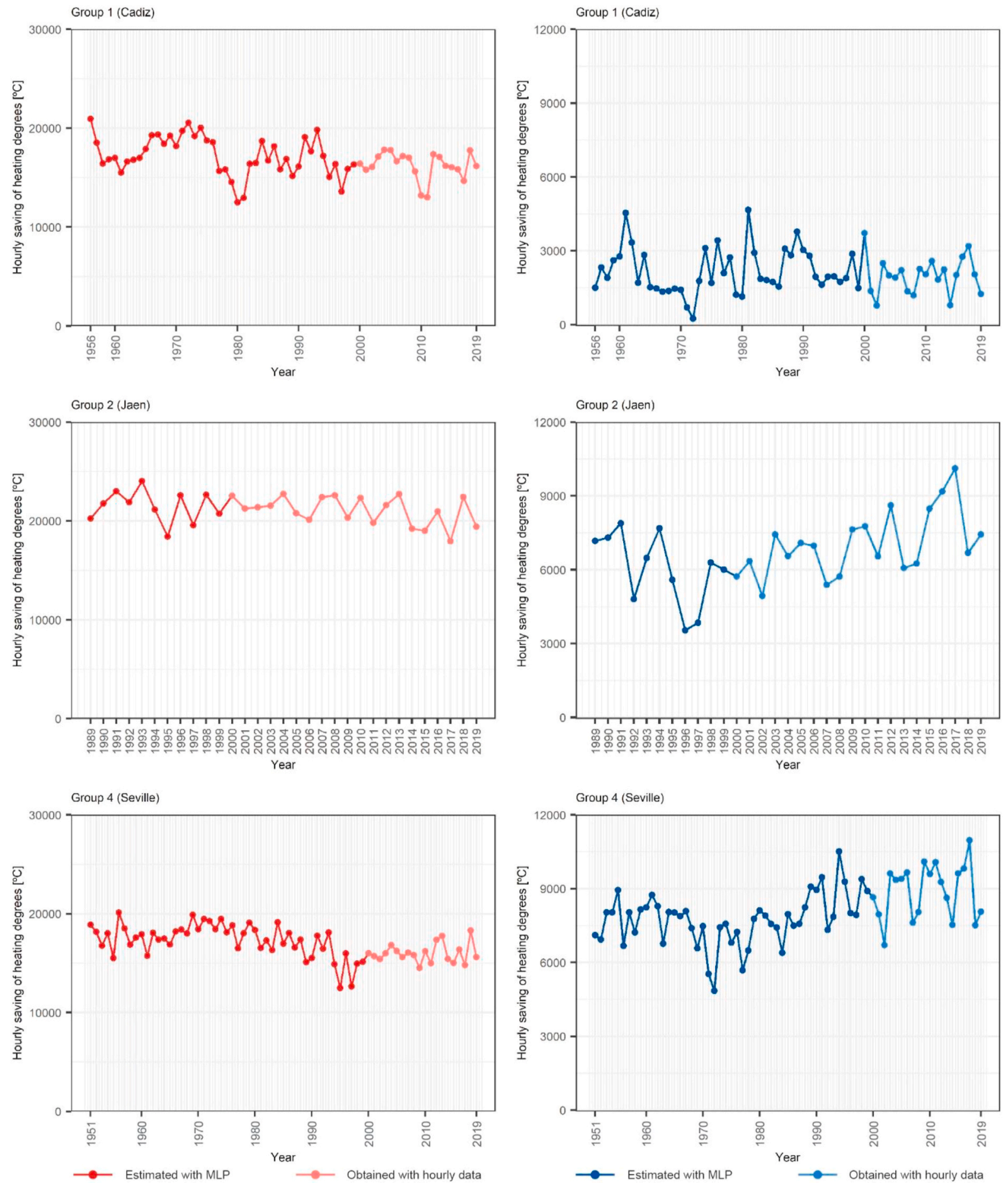

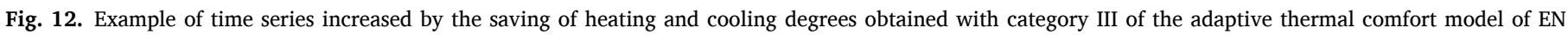
16798-1:2019 in the period between the oldest year available for clusters and 2019. The results before the year 2000 were obtained through the MLPs.

degrees were low. Accordingly, clusters 1 and 3 were characterised as presenting lower values of cooling degrees, whereas clusters 2 and 4 obtained higher values. In addition, all clusters obtained high values of heating degrees, although cluster 3 obtained greater values, while cluster 1 obtained lower values. In addition, the possible variability presented by the energy demand of a building according to the climate conditions of each year was shown, as some years, such as 2017, were characterised as presenting greater demands for cooling degrees.

These heating and cooling demands, required to acclimatise the indoor spaces according to the static setpoint temperature, clearly influenced the degree-saving obtained by the adaptive setpoint temperatures (Figs. 7 and 8). Moreover, as in the case of ventilation, users' thermal expectations could influence the savings achieved. In this regard, the clusters with lower values of heating degrees and the most demanding categories of thermal expectation (i.e. categories I and II) obtained negative values. In these cases, only category III obtained savings of heating degrees. Only the savings obtained with respect to the use of a static setpoint temperature with a high thermal expectation of the user (i.e. $22{ }^{\circ} \mathrm{C}$ ) were positive. This aspect resulted from the behaviour of the adaptive setpoint temperatures obtained through the 
Table 6

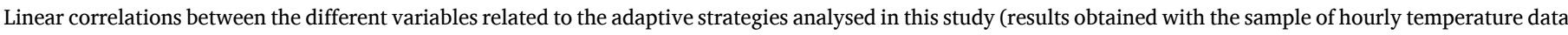
between 2000 and 2019).

\begin{tabular}{|c|c|c|c|c|}
\hline Variable & Group 1 & Group 2 & Group 3 & Group 4 \\
\hline Percentage of days of application & $y=61.3+0.02 \cdot x$ & $y=413.44-0.17 \cdot x$ & $y=152.29-0.04 \cdot x$ & $y=100.39-0.01 \cdot x$ \\
\hline Percentage of days in which the upper limit is overcome & $y=0.37-0.01 \cdot x$ & $y=-155.26+0.08 \cdot x$ & $y=2381.10-1.23 \cdot x$ & $y=-139.79+0.071 \cdot x$ \\
\hline Percentage of days in which the lower limit is overcome & $y=38.33-0.02 \cdot x$ & $y=-158.18+0.09 \cdot x$ & $y=-57.24+0.05 \cdot x$ & $y=139.4-0.07 \cdot x$ \\
\hline Percentage of hours of natural ventilation (category I) & $y=-17.17+0.02 \cdot x$ & $y=-81.71+0.05 \cdot x$ & $y=-69.93+0.04 \cdot x$ & $y=0.56+0.01 \cdot x$ \\
\hline Percentage of hours of natural ventilation (category II) & $y=-87.73+0.06 \cdot x$ & $y=-25.72+0.02 \cdot x$ & $y=-103.97+0.06 \cdot x$ & $y=-15.54+0.02 \cdot x$ \\
\hline Percentage of hours of natural ventilation (category III) & $y=-207.99+0.12 \cdot x$ & $y=-65.95+0.05 \cdot x$ & $y=-128.47+0.07 \cdot x$ & $y=-76.49+0.05 \cdot x$ \\
\hline Hourly heating degrees $\left(20^{\circ} \mathrm{C}\right)$ & $y=220701.95-97.93 \cdot x$ & $y=164697.01-60.09 \cdot x$ & $y=200148.8-67.9 \cdot x$ & $y=344827.7-155.7 \cdot x$ \\
\hline Hourly heating degrees $\left(21^{\circ} \mathrm{C}\right)$ & $\begin{array}{l}y=247516.22-108.64 \\
x\end{array}$ & $y=207576.75-78.60 \cdot x$ & $y=228690.76-78.62 \cdot x$ & $y=370128.5-165.7 \cdot x$ \\
\hline Hourly heating degrees $\left(22^{\circ} \mathrm{C}\right)$ & $\begin{array}{l}y=272899.58-118.32 \\
x\end{array}$ & $y=246660.45-95.08 \cdot x$ & $y=253151-87.2 \cdot x$ & $y=392065.58-173.88 \cdot x$ \\
\hline Hourly cooling degrees $\left(25^{\circ} \mathrm{C}\right)$ & $y=2609.02-0.27 \cdot x$ & $y=-134786.12+71.06 \cdot x$ & $y=-48949.04+25.62 \cdot x$ & $y=-63680.63+37.12 \cdot x$ \\
\hline Hourly cooling degrees $\left(26^{\circ} \mathrm{C}\right)$ & $y=5687.14-2.2 \cdot x$ & $y=-114487.87+60.12 \cdot x$ & $y=-37013.15+19.32 \cdot x$ & $y=-53354.18+31.02 \cdot x$ \\
\hline Hourly cooling degrees $\left(27^{\circ} \mathrm{C}\right)$ & $y=7482.49-3.33 \cdot x$ & $y=-103393.3+53.9 \cdot x$ & $y=-26011.84+13.57 \cdot x$ & $y=-51127.66+29.07 \cdot x$ \\
\hline Hourly heating degrees (category I - $20^{\circ} \mathrm{C}$ ) & $y=15019.06-11.33 \cdot x$ & $y=-49776.04+23.23 \cdot x$ & $y=43742.44-22.5 \cdot x$ & $y=11580.19-8.97 \cdot x$ \\
\hline Hourly heating degrees (category I - $21^{\circ} \mathrm{C}$ ) & $y=38680.56-20.48 \cdot x$ & $y=-2580.11+2.57 \cdot x$ & $y=72284.44-33.24 \cdot x$ & $y=39845.59-20.46 \cdot x$ \\
\hline Hourly heating degrees (category I $-22^{\circ} \mathrm{C}$ ) & $y=61321.94-28.8 \cdot x$ & $y=48227.24-19.74 \cdot x$ & $y=96744.73-41.82 \cdot x$ & $y=66505.99-30.95 \cdot x$ \\
\hline Hourly cooling degrees (category I - $25^{\circ} \mathrm{C}$ ) & $y=9889.58-3.98 \cdot x$ & $y=-102676.58+54.02 \cdot x$ & $y=-35264.9+18.49 \cdot x$ & $y=-46414.45+26.58 \cdot x$ \\
\hline Hourly cooling degrees (category I - $26^{\circ} \mathrm{C}$ ) & $y=3615.77-1.28 \cdot x$ & $y=-78411.23+41.11 \cdot x$ & $y=-23329.01+12.2 \cdot x$ & $y=-39231.63+22.04 \cdot x$ \\
\hline Hourly cooling degrees (category I - $27^{\circ} \mathrm{C}$ ) & $y=2081.28-0.77 \cdot x$ & $y=-56186.57+29.35 \cdot x$ & $y=-12327.69+6.45 \cdot x$ & $y=-31280.64+17.27 \cdot x$ \\
\hline Hourly heating degrees (category II $-20^{\circ} \mathrm{C}$ ) & $y=26632.32-13.77 \cdot x$ & $y=-14198.98+8.69 \cdot x$ & $y=64843.76-29.37 \cdot x$ & $y=32040.6-16.15 \cdot x$ \\
\hline Hourly heating degrees (category II $-2{ }^{\circ} \mathrm{C}$ ) & $y=51853.78-23.69 \cdot x$ & $y=38674.43-14.79 \cdot x$ & $y=93385.76-40.11 \cdot x$ & $y=59019.32-27 \cdot x$ \\
\hline Hourly heating degrees (category II $-22^{\circ} \mathrm{C}$ ) & $y=73783.43-31.66 \cdot x$ & $y=86218.74-35.47 \cdot x$ & $y=117846.05-48.69 \cdot x$ & $y=84302.33-36.82 \cdot x$ \\
\hline Hourly cooling degrees (category II $-25^{\circ} \mathrm{C}$ ) & $y=9760.82-3.86 \cdot x$ & $y=-115351.27+60.67 \cdot x$ & $y=-40388.4+21.18 \cdot x$ & $y=-49553.9+28.64 \cdot x$ \\
\hline Hourly cooling degrees (category II $-26^{\circ} \mathrm{C}$ ) & $y=4602.37-1.7 \cdot x$ & $y=-90641.95+47.54 \cdot x$ & $y=-28452.51+14.88 \cdot x$ & $y=-41764.24+23.8 \cdot x$ \\
\hline Hourly cooling degrees (category II - $27^{\circ} \mathrm{C}$ ) & $y=2849.39-1.09 \cdot x$ & $y=-67203.78+35.17 \cdot x$ & $y=-17451.194+9.133 \cdot x$ & $y=-33579.96+18.92 \cdot x$ \\
\hline Hourly heating degrees (category III $-20^{\circ} \mathrm{C}$ ) & $y=45727.77-20.33 \cdot x$ & $y=28771.91-9.72 \cdot x$ & $y=85591.87-36.21 \cdot x$ & $y=54406.68-24.51 \cdot x$ \\
\hline Hourly heating degrees (category III - $21^{\circ} \mathrm{C}$ ) & $y=70306.13-29.93 \cdot x$ & $y=78245.15-31.51 \cdot x$ & $y=114133.87-46.95 \cdot x$ & $y=80755.97-35.05 \cdot x$ \\
\hline Hourly heating degrees (category III $-22^{\circ} \mathrm{C}$ ) & $y=91570.62-37.57 \cdot x$ & $y=122644.65-50.62 \cdot x$ & $y=138594.16-55.52 \cdot x$ & $y=104739.87-44.23 \cdot x$ \\
\hline Hourly cooling degrees (category III - $25^{\circ} \mathrm{C}$ ) & $y=7483.77-2.7 \cdot x$ & $y=-127623.62+67.02 \cdot x$ & $y=-42479.12+22.3 \cdot x$ & $y=-50550.96+29.54 \cdot x$ \\
\hline Hourly cooling degrees (category III $-26^{\circ} \mathrm{C}$ ) & $y=4489.23-1.61 \cdot x$ & $y=-98896.03+51.90 \cdot x$ & $y=-30543.22+16.01 \cdot x$ & $y=-45235.01+25.94 \cdot x$ \\
\hline Hourly cooling degrees (category III $-27^{\circ} \mathrm{C}$ ) & $y=3032.15-1.15 \cdot x$ & $y=-72987.72+38.30 \cdot x$ & $y=-19541.91+10.26 \cdot x$ & $y=-37045.97+21.06 \cdot x$ \\
\hline
\end{tabular}

linear correlations of $t_{r m}$. A high $t_{r m}$ value implies that, in the hours of heating demand, the adaptive setpoint temperature obtained for categories I and II is greater than the static setpoint temperature. Thus, a successful saving can only be obtained in these regions if the adaptive setpoint temperatures from category III are used; for the other two categories, it would be interesting to consider a static approach as the effectiveness of these setpoint temperatures can be reduced if the user does not have patterns of high thermal expectation. This same tendency was observed in the other two clusters, although the greatest heating demand generated the greatest effectiveness of using the adaptive setpoint temperatures of categories I and II. In this regard, only the saving of category I with respect to a static setpoint temperature of $20{ }^{\circ} \mathrm{C}$ was negative. Therefore, the use of these adaptive setpoint temperatures for heating generated substantial energy-saving in cold regions. In this regard, cluster 3 obtained savings of heating degrees between $22,989.62{ }^{\circ} \mathrm{C}$ and $29,670.55{ }^{\circ} \mathrm{C}$ with category III.

Regarding the savings from cooling degrees, the values mainly depended on the demand of cooling degree, as indicated in Fig. 6. In this regard, the saving values of cooling degrees were greater in the zones with greater demand (clusters 2 and 4). However, even in clusters with lower saving and compared to a highly efficient static setpoint temperature $\left(27^{\circ} \mathrm{C}\right)$, the obtained results were always greater than 0 , thus reflecting the possibility of applying adaptive thermal comfort models to achieve considerable saving of the building cooling demand. In addition, there is a huge potential of applying adaptive strategies, as the adequacy of nZEB in the countries from the south of Spain is challenging [63].

\subsection{Application of adaptive strategies from the 20th century to nowadays}

As indicated in Subsection 3.2., the potential of energy-saving with adaptive strategies presented acceptable results in the four clusters analysed. This analysis was conducted with the hourly temperature data between 2000 and 2019. However, Table 1 indicates that there were daily time series of the 20 th century in clusters 1,2 , and 4 . Therefore, the determination of variables related to adaptive thermal comfort strategies would allow the tendencies of evolution of the strategies to be found with the recorded data. Only the results related to the percentage of days to apply adaptive thermal comfort models could be determined with daily temperature data, and thus, the results were estimated at an hourly scale (i.e. natural ventilation and saving of heating and cooling degrees) by using MLPs. For this purpose, individual MLPs were designed for each output variable, and the maximum, minimum, and average temperatures of each month were used as the input variables (Table 4). A total of 27 MLPs were designed. The dataset used in the analysis was designed with the data obtained for the cluster analysis, as well as the hourly data of the cities of Cadiz, Jaen, Grazalema, and Seville. MLPs were trained with $75 \%$ of a random data sample, while the remaining $25 \%$ was used for the testing.

Table 5 indicates the performance of the MLPs in the training and testing phases, and Fig. 9 shows the dispersion diagrams among the actual and simulated values. The performance achieved by the MLPs was satisfactory. In this regard, in the testing phase, the values of the determination coefficient were above $90 \%$ in most MLPs. Only MLP-10 (hourly heating degrees (category I - $20{ }^{\circ} \mathrm{C}$ )) and MLP-12 (hourly heating degrees (category I $-22^{\circ} \mathrm{C}$ )) obtained lower values for the 
determination coefficient. Regarding the error parameters, the values obtained were satisfactory, because according to the variables analysed, the values obtained showed an appropriate adjustment degree. The performances achieved by the MLPs, therefore, indicated the possibility of using these models for estimating the energy-saving variables with adaptive strategies of daily time series. Thus, the potential application of adaptive thermal comfort models was first determined based on daily data (Fig. 10), and then, the MLPs were used to estimate the possibilities of natural ventilation (Fig. 11) and the saving of heating and cooling degrees (Fig. 12).

By analysing the adaptive variables of energy-saving, the analysis of the possible application of adaptive thermal comfort models was started again. An analysis of the overall series verified that the application percentages obtained by the records throughout the 20th century presented similar values to those obtained throughout the 21 st century. However, there were different tendencies of evolution at these values. Using the results obtained by the overall series in each cluster (in cluster 3 , there were only hourly results between 2001 and 2019), linear correlations were determined in the time series, which reflected the tendencies of evolution (Table 6). This analysis showed that the potential application of adaptive thermal comfort models presented a slightly downward tendency, with cluster 2 being the only exception, as it exhibited a greater downward tendency. In cluster 1 , there was an almost uniform tendency as the percentage of application was mainly $100 \%$. Regarding the reasons for the decrease in the application of adaptive models, three tendencies were observed in each cluster: (i) the decrease in cluster 2 was due to the percentage of days in which the lower and upper limits were overcome; (ii) in cluster 3, it was due to an increase in the percentage of days with cold temperatures (with $t_{r m}$ lower than $10^{\circ} \mathrm{C}$ ); and (iii) in cluster 4 , it was due to an increase in the number of hot days (with $t_{r m}$ greater than $30{ }^{\circ} \mathrm{C}$ ). Nonetheless, these tendencies, although there was a downward tendency in most clusters, did not constitute a negative factor with respect to the potential application of the adaptive strategies, as in general, the values obtained by the adaptive models were greater than $50 \%$ of the days of the year, and these downward tendencies could be a sign of the climate variation predicted throughout the 21 st century.

There was, therefore, a downward tendency in the days to apply the adaptive thermal comfort models. However, the effectiveness of applying adaptive energy-saving strategies presented different tendencies. First, the possibilities of natural ventilation showed a clear ascending tendency in the four clusters and three categories of EN 16798-1:2019. As for the saving of heating and cooling degrees, different tendencies were observed according to the type of energy demand to be met: the saving of heating degrees showed a downward tendency in all clusters due to the decreasing tendency presented by heating requirements, whereas the saving of cooling degrees showed an ascending tendency, which results from the ascending tendency of the cooling requirements of buildings. These results agreed with the increasing tendency of external temperatures, which have resulted from the evolutions of climate change since the end of the 20th century.

\section{Conclusions}

This study analysed the potential application of adaptive energysaving strategies in the 786 Andalusian municipalities (in the south of Spain) through the international EN 16798-1:2019 standard. From a multi-dimensional cluster analysis, considering the use of natural ventilation and adaptive setpoint temperatures, four groups were determined based on the climatic parameters. Clusters 1 and 4 exhibited the greatest population, with cluster 1 obtaining lower income per person and clusters 2 and 3 obtaining lower income per household. Furthermore, the cluster analysis showed the relation between the geographical characteristics of a region and the application of adaptive models. In this study, the groups corresponded to municipalities with similar geographic characteristics, such as municipalities located in coastal areas, those located in the depression of the Guadalquivir River, or those located in the Baetic System. Therefore, these results agree with those of the studies conducted on a global scale, where the relation between adaptive models and geographic characteristics was detected. This forms a basis for the development of climatic zones for the application of adaptive models. In this sense, the groups obtained in the cluster analysis showed variation with respect to the climatic zones established in the Spanish Building Technical Code. However, these differences are normal as both the classification criteria and objectives differed for the two climatic zones. Nevertheless, the differences serve as a basis for discussing the needs to establish new climatic zones in the country or developing new regulatory criteria.

Regarding the analysis of historical data, a representative city was selected for each cluster: Cadiz for cluster 1, Jaen for cluster 2, Grazalema for cluster 3, and Seville for cluster 4. This study showed that the applicability of an adaptive thermal comfort model had substantial potential in all four clusters within the temporary framework of 2000-2019, ranging between $100 \%$ for cluster 1 and $69 \%$ for cluster 3 .

As for the potential of natural ventilation, two main conclusions were drawn by considering the three categories studied. First, the applicability of this strategy was never below $10 \%$ (cluster 3), even at the most restrictive level of expectation (Category I), being at $\sim 15 \%$ in clusters 2 and 4 and $\sim 20 \%$ in cluster 1 . Second, considering the least restrictive level of expectation usually applied to an existing building (Category III), the percentage substantially increased in cluster 1 , being close to $40 \%$ of the hours of the year, increasing by $\sim 30 \%$ in clusters 2 and 4 , and by more than $20 \%$ in cluster 3 . As a result, the substantial potential of natural ventilation as a strategy for energy reduction is proved, even in the coldest zones (cluster 3) studied.

In addition, this study showed that the energy-saving strategy through the application of adaptive setpoints to regulate the consumption of HVAC systems led to a substantial saving of the heating and cooling degrees required with respect to six configurations of static setpoints: three for heating $\left(20^{\circ} \mathrm{C}, 21^{\circ} \mathrm{C}\right.$, and $\left.22^{\circ} \mathrm{C}\right)$ and three for cooling $\left(25^{\circ} \mathrm{C}, 26^{\circ} \mathrm{C}\right.$, and $\left.27^{\circ} \mathrm{C}\right)$. The results showed that users' thermal expectations, as in the case of natural ventilation, substantially influenced the saving of heating and cooling degrees. Considering the former, only Category III implied saving in all cases, with clusters 2 and 3 being the most stressed. However, comparing Category I with static setpoints, saving was achieved in clusters 1 and 4 only with the most restrictive setpoint $\left(22^{\circ} \mathrm{C}\right)$, whereas that in clusters 2 and 3 was achieved at setpoint of $21^{\circ} \mathrm{C}$. This tendency is contrary to that observed for the saving of cooling degrees, where all cases maintained positive values, thus stressing the potential of using adaptive setpoints in the cooling regime to achieve substantial reduction in energy consumption.

By considering the analysis of old time series with the design of 27 MLPs, the following conclusions can be drawn based on the evolution presented by these series considering the increasing tendency of external temperatures due to climate change. There was, therefore, a slight downward trend in the application of adaptive thermal comfort models in the days. However, with a decrease in saving of heating degrees, the natural ventilation strategy substantially increased in all clusters, followed by the saving of cooling degrees. These results can be useful in understanding, with real data, the expected evolution trend of the energy performance of existing buildings and facilitate their transition to buildings with almost zero energy consumption. The expected higher energy demand for cooling in buildings may limit the use of energysaving measures, such as improving the envelope of buildings (a measure more focused on reducing the energy demand for heating). In this circumstance, an adaptive behaviour by users would reduce the energy demand for cooling in buildings and guarantee better resilience to the expected evolution of the climate.

These results, therefore, showed the potential application of adaptive strategies for reducing the energy consumption. The use of natural ventilation strategies and cooling adaptive setpoint temperatures can substantially save building energy consumption, and in turn, reduce 
GHGs. Further studies should consider several climate change scenarios in Andalusia. The results of this study show the need to implement adaptive behaviours in the conditioning of interior spaces. For this purpose, the use of automation processes in HVAC systems and smartphone applications can facilitate a better implementation of adaptive strategies. Likewise, it is necessary to develop awareness policies so that users know the advantages of adaptive strategies, similar to that conducted in Japan with the 'Super cool biz' campaign [64]. Regarding the limitations of this study, the recently detected trend for the application of adaptive models has not analysed the scenarios foreseen by the Intergovernmental Panel on Climate Change. These scenarios should be analysed in the future to observe the expected trend throughout the 21st century. Second, the analysis did not consider the period of permanence of users in buildings. In this sense, an adaptive behaviour by users based on moving to areas with more favourable thermal conditions (e.g. going to coastal areas during the summer) can change the expected trends in energy demand. However, long-term episodes of users in their homes, such as the COVID-19 pandemic, may limit the application of these travel strategies to other regions. Finally, the relation that can be presented between the application of adaptive strategies and the decrease in cases of energy poverty constitutes a future aspect to be studied. The study results have shown how the different clusters are characterised as having municipalities with low-middle income. Thus, the use of these strategies is an opportunity for these families to condition their interior spaces. However, the following two knowledge gaps need to be addressed in the future. First, a precise evaluation of the relation between the population and income of the census units of each municipality, with the potential of applying adaptive strategies, needs to be conducted. Therefore, future research should be oriented towards smallor medium-scale studies in a similar manner to those conducted by Sánchez et al. [65] in Madrid. Second, the possibility that users are already using adaptive approaches in the region indicates that family assessment procedures, such as those based on the energy rating of buildings, overestimate the energy consumption of buildings and generate 'false positives' in case of energy poverty. The analysis of these cases should be addressed in the future through surveys that provide detailed information on the predominant type of behaviour exhibited by users in each municipality.

\section{Declaration of competing interest}

The authors declare that they have no known competing financial interests or personal relationships that could have appeared to influence the work reported in this paper.

\section{Acknowledgement}

The authors would like to acknowledge to the research project "Nuevo Análisis Integral de la Pobreza Energética en Andalucía (NAIPE). Predicción, evaluación y adaptación al cambio climático de hogares vulnerables desde una perspectiva económica, ambiental y social (US125546)" funded by the European Regional Development Fund (ERDF) and by the "Consejería de Economía y Conocimiento de la Junta de Andalucía (Spain)" for support this research.

\section{References}

[1] Intergovernmental Panel on Climate Change, Climate Change 2007: the Physical Science Basis. Contribution of Working Group I to the Fourth Assessment Report of the Intergovernmental Panel on Climate Change, 2007.

[2] Intergovernmental Panel on Climate Change, Climate Change 2014: Synthesis Report. Contribution of Working Groups I, II and III to the Fifth Assessment Report of the Intergovernmental Panel on Climate Change, Cambridge University Press, Cambridge, 2014, https://doi.org/10.1017/CBO9781107415324.004.

[3] World Meteorological Organization, United in Science, 2019.

[4] European Commission, Directive 2002/91/EC of the European Parliament and of the Council of 16 December 2002 on the Energy Performance of Buildings, vol. 1, 2002. Brussels, Belgium.
[5] European Union, Directive 2010/31/EU of the European Parliament and of the Council of 19 May 2010 on the Energy Performance of Buildings, vol. 153, 2010. Brussels, Belgium.

[6] European Commission, A Roadmap for Moving to a Competitive Low Carbon Economy in 2050, 2011. Brussels, Belgium.

[7] International Energy Agency, Energy efficiency 2017. https://doi.org/10.1787/97 89264284234-en, 2017.

[8] R. Galvin, A. Gubernat, The rebound effect and Schatzki's social theory: reassessing the socio-materiality of energy consumption via a German case study, Energy Res Soc Sci 22 (2016) 183-193, https://doi.org/10.1016/j.erss.2016.08.024.

[9] A. Allouhi, Y. El Fouih, T. Kousksou, A. Jamil, Y. Zeraouli, Y. Mourad, Energy consumption and efficiency in buildings: current status and future trends, J. Clean. Prod. 109 (2015) 118-130, https://doi.org/10.1016/j.jclepro.2015.05.139.

[10] K.K.W. Wan, D.H.W. Li, J.C. Lam, Assessment of climate change impact on building energy use and mitigation measures in subtropical climates, Energy 36 (2011) 1404-1414, https://doi.org/10.1016/j.energy.2011.01.033.

[11] G.N. Spyropoulos, C.A. Balaras, Energy consumption and the potential of energy savings in Hellenic office buildings used as bank branches - a case study, Energy Build. 43 (2011) 770-778, https://doi.org/10.1016/j.enbuild.2010.12.015.

[12] T. Hoyt, E. Arens, H. Zhang, Extending air temperature setpoints: simulated energy savings and design considerations for new and retrofit buildings, Build. Environ. 88 (2014) 89-96, https://doi.org/10.1016/j.buildenv.2014.09.010.

[13] P.O. Fanger, Thermal Comfort: Analysis and Applications in Environmental Engineering, 1970. New York.

[14] G.S. Brager, R.J. De Dear, Thermal adaptation in the built environment: a literature review, Energy Build. 27 (1998) 83-96, https://doi.org/10.1016/s0378-7788(97) 00053-4.

[15] S. Carlucci, L. Bai, R. de Dear, L. Yang, Review of adaptive thermal comfort models in built environmental regulatory documents, Build. Environ. 137 (2018) 73-89, https://doi.org/10.1016/j.buildenv.2018.03.053.

[16] S. Aghniaey, T.M. Lawrence, The impact of increased cooling setpoint temperature during demand response events on occupant thermal comfort in commercial buildings: a review, Energy Build. 173 (2018) 19-27, https://doi.org/10.1016/j. enbuild.2018.04.068.

[17] M. Humphreys, Field Studies in Thermal Comfort Compared and Applied, 1975.

[18] M. Humphreys, Outdoor temperatures and comfort indoors, Build Res Pract 6 (1978) 92, https://doi.org/10.1080/09613217808550656.

[19] J.F. Nicol, M.A. Humphreys, Thermal comfort as part of a self-regulating system, Build Res Pract 1 (1973) 174-179, https://doi.org/10.1080/09613217308550237.

[20] R. de Dear, G.S. Brager, Developing an Adaptive Model of Thermal Comfort and Preference, 1998.

[21] R. de Dear, G.S. Brager, Thermal comfort in naturally ventilated buildings: revision to ASHRAE standards 55, J Energy Build 34 (2002) 549-561, https://doi.org/ 10.1016/S0378-7788(02)00005-1.

[22] R. De Dear, G.S. Brager, The adaptive model of thermal comfort and energy conservation in the built environment, Int. J. Biometeorol. 45 (2001) 100-108.

[23] K.J. McCartney, J.F. Nicol, Developing an adaptive control algorithm for Europe, Energy Build. 34 (2002) 623-635.

[24] European Committee for Standardization, EN 15251:2007 Indoor Environmental Input Parameters for Design and Assessment of Energy Performance of Buildings Addressing Indoor Quality, Thermal Environment, Lighting and Acoustics, European Committee for Standardization, Brussels, 2007.

[25] European Committee for Standardization, EN 16798-1:2019 Energy Performance of Buildings - Ventilation for Buildings - Part 1: Indoor Environmental Input Parameters for Design and Assessment of Energy Performance of Buildings Addressing Indoor Air Quality, Thermal Environment, Lighting and Acous, 2019.

[26] S. Carlucci, L. Bai, R. de Dear, L. Yang, Review of adaptive thermal comfort models in built environmental regulatory documents, Build. Environ. 137 (2018) 73-89, https://doi.org/10.1016/J.BUILDENV.2018.03.053.

[27] J.C. Salcido, A.A. Raheem, R.R.A. Issa, From simulation to monitoring: evaluating the potential of mixed-mode ventilation (MMV) systems for integrating natural ventilation in office buildings through a comprehensive literature review, Energy Build. 127 (2016) 1008-1018, https://doi.org/10.1016/j.enbuild.2016.06.054.

[28] S. Ezzeldin, S.J. Rees, The potential for office buildings with mixed-mode ventilation and low energy cooling systems in arid climates, Energy Build. 65 (2013) 368-381, https://doi.org/10.1016/j.enbuild.2013.06.004.

[29] J. Chen, G. Augenbroe, X. Song, Evaluating the potential of hybrid ventilation for small to medium sized office buildings with different intelligent controls and uncertainties in US climates, Energy Build. 158 (2018) 1648-1661, https://doi. org/10.1016/j.enbuild.2017.12.004.

[30] D. Sánchez-García, C. Rubio-Bellido, M. Tristancho, M. Marrero, A comparative study on energy demand through the adaptive thermal comfort approach considering climate change in office buildings of Spain, Build Simul 1-13 (2019), https://doi.org/10.1007/s12273-019-0560-2.

[31] D. Bienvenido-Huertas, D. Sánchez-García, C. Rubio-Bellido, Comparison of energy conservation measures considering adaptive thermal comfort and climate change in existing Mediterranean dwellings, Energy 190 (2020), https://doi.org/10.1016/ j.energy.2019.116448.

[32] D. Bienvenido-Huertas, D. Sánchez-García, C. Rubio-Bellido, M.J. Oliveira, Influence of adaptive energy saving techniques on office buildings located in cities of the Iberian Peninsula, Sustain Cities Soc 53 (2020) 101944, https://doi.org/ 10.1016/j.scs.2019.101944.

[33] D. Bienvenido-Huertas, D. Sánchez-García, A. Pérez-Fargallo, C. Rubio-Bellido, Optimization of energy saving with adaptive setpoint temperatures by calculating the prevailing mean outdoor air temperature, Build. Environ. 170 (2020), https:// doi.org/10.1016/j.buildenv.2019.106612. 
[34] D. Bienvenido-Huertas, C. Rubio-Bellido, A. Pérez-Fargallo, J.A. Pulido-Arcas, Energy saving potential in current and future world built environments based on the adaptive comfort approach, J. Clean. Prod. 249 (2020) 119306, https://doi. org/10.1016/j.jclepro.2019.119306.

[35] R. Castaño-Rosa, J. Solís-Guzmán, M. Marrero, Energy poverty goes south? Understanding the costs of energy poverty with the index of vulnerable homes in Spain, Energy Res Soc Sci 60 (2020) 101325, https://doi.org/10.1016/j. erss.2019.101325.

[36] European Commission, Communication from the commission, Europe 2020, Igarss 2014 (2014) 1-5, https://doi.org/10.1007/s13398-014-0173-7.2.

[37] S. Tirado Herrero, L. Jiménez Meneses, J.L. López Fernández, E. Perero Van Hove, V.M. Irigoyen Hidalgo, P. Savary, Poverty, Vulnerability and Energy Inequality. New Approaches to Analysis. 1a. Madrid, 2016.

[38] D. Sánchez-García, D. Bienvenido-Huertas, M. Tristancho-Carvajal, C. RubioBellido, Adaptive comfort control implemented model (accim) for energy consumption predictions in dwellings under current and future climate conditions: a case study located in Spain, Energies 12 (2019) 1498, https://doi.org/10.3390/ en12081498.

[39] D. Sánchez-García, C. Rubio-Bellido, J.J.M. del Río, A. Pérez-Fargallo, Towards the quantification of energy demand and consumption through the adaptive comfort approach in mixed mode office buildings considering climate change, Energy Build. 187 (2019) 173-185, https://doi.org/10.1016/j.enbuild.2019.02.002.

[40] A.A. Alola, S Saint Akadiri, A.C. Akadiri, U.V. Alola, A.S. Fatigun, Cooling and heating degree days in the US: the role of macroeconomic variables and its impact on environmental sustainability, Sci. Total Environ. 695 (2019) 133832, https:// doi.org/10.1016/j.scitotenv.2019.133832.

[41] D. Bienvenido-Huertas, J.A. Pulido-Arcas, C. Rubio-Bellido, A. Pérez-Fargallo, Influence of future climate changes scenarios on the feasibility of the adaptive comfort model in Japan, Sustain Cities Soc 61 (2020) 102303, https://doi.org/ 10.1016/j.scs.2020.102303.

[42] The Government of Spain, Royal Decree 314/2006. Approving the Spanish Technical Building Code, 2013. Madrid, Spain.

[43] J.A. Hartigan, M.A. Wong, Algorithm AS 136: a k-means clustering algorithm, J R Stat Soc Ser C (Applied Stat 28 (1979) 100-108.

[44] D.J. Ketchen, C.L. Shook, The application of cluster analysis in strategic management research: an analysis and critique, Strat. Manag. J. 17 (1996) 441-458, https://doi.org/10.1002/(sici)1097-0266(199606)17:6<441::aidsmj819>3.0.co;2-g.

[45] L. Kaufman, P.J. Rousseeuw, An Introduction to Cluster Analysis, John Wiley and Sons, Incorporated, 1990.

[46] S.S. Haykin, S.S. Haykin, S.S. Haykin, S.S. Haykin, Neural Networks and Learning Machines, vol. 3, Pearson Upper, Saddle River, 2009.

[47] A.R. Barron, Universal approximation bounds for superpositions of a sigmoidal function, IEEE Trans. Inf. Theor. 39 (1993) 930-945.

[48] G. Cybenko, Approximation by superpositions of a sigmoidal function, Math Control Signals Syst 2 (1989) 303-314.
[49] K. Hornik, M. Stinchcombe, H. White, Multilayer feedforward networks are universal approximators, Neural Network. 2 (1989) 359-366, https://doi.org/ 10.1016/0893-6080(89)90020-8.

[50] D. Bienvenido-Huertas, C. Rubio-Bellido, J.L. Pérez-Ordóñez, J. Moyano, Optimizing the evaluation of thermal transmittance with the thermometric method using multilayer perceptrons, Energy Build. 198 (2019) 395-411, https://doi.org/ 10.1016/j.enbuild.2019.06.040.

[51] R. Kumar, R.K. Aggarwal, J.D. Sharma, Energy analysis of a building using artificial neural network: a review, Energy Build. 65 (2013) 352-358, https://doi.org/ 10.1016/j.enbuild.2013.06.007.

[52] D.E. Rumelhart, G.E. Hinton, R.J. Williams, Learning representations by backpropagating errors, Nature 323 (1986) 533-536, https://doi.org/10.1038/ $323533 \mathrm{a} 0$.

[53] Y.N. Wang, A neural network adaptive control based on rapid learning method and application, Adv Molding Anal 46 (1994) 27-34.

[54] P. Werbos, Beyond Regression: New Tools for Prediction and Analysis in the Behavior Science, Harvard University, 1974.

[55] R. Fletcher, Practical Methods of Optimization, John Wiley\&Sons; Chichester New York - Brisbane - Toronto, United States, 1980.

[56] L. Bellia, A. Pedace, F. Fragliasso, The role of weather data files in Climate-based Daylight Modeling, Sol. Energy 112 (2015) 169-182, https://doi.org/10.1016/j. solener.2014.11.033.

[57] S. Hatwaambo, P.C. Jain, B. Perers, B. Karlsson, Projected beam irradiation at low latitudes using Meteonorm database, Renew. Energy 34 (2009) 1394-1398, https://doi.org/10.1016/j.renene.2008.09.011.

[58] M.M. Osman, H. Sevinc, Adaptation of climate-responsive building design strategies and resilience to climate change in the hot/arid region of Khartoum, Sudan, Sustain Cities Soc 47 (2019) 101429, https://doi.org/10.1016/j. scs.2019.101429.

[59] M. Kameni, A. Yvon, O. Kalameu, S. Asadi, R. Choudhary, S. Reiter, Impact of climate change on demands for heating and cooling energy in hospitals : an indepth case study of six islands located in the Indian Ocean region, Sustain Cities Soc 44 (2019) 629-645, https://doi.org/10.1016/j.scs.2018.10.031.

[60] Meteonorm, Handbook Part II: Theory, Bern, Switzerland, 2019, Version 7.3.1.

[61] Spanish Institute of Statistics, Atlas of distribution of household income 2019. htt ps://www.ine.es/experimental/experimental.htm.

[62] Spanish Institute of Statistics, Demography and population 2020. https://www.ine. es/dyngs/INEbase/es/categoria.htm?c=Estadistica_P\&cid=1254734710984.

[63] S. Attia, P. Eleftheriou, F. Xeni, R. Morlot, C. Ménézo, V. Kostopoulos, et al., Overview and future challenges of nearly zero energy buildings (nZEB) design in Southern Europe, Energy Build. 155 (2017) 439-458, https://doi.org/10.1016/j. enbuild.2017.09.043.

[64] M. Indraganti, R. Ooka, H.B. Rijal, Thermal comfort in offices in summer: findings from a field study under the "setsuden" conditions in Tokyo, Japan, Build. Environ. 61 (2013) 114-132, https://doi.org/10.1016/j.buildenv.2012.12.008.

[65] C. Sánchez-Guevara Sánchez, A. Sanz Fernández, M. Núñez Peiró, G. Gómez Muñoz, Energy poverty in Madrid: data exploitation at the city and district level, Energy Pol. 144 (2020), https://doi.org/10.1016/j.enpol.2020.111653. 